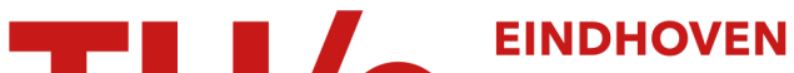 UNIVERSITY OF TECHNOLOGY
}

\section{Large-scale forcing effects on wind flows in the urban canopy}

\section{Citation for published version (APA):}

Ricci, A., Kalkman, I., Blocken, B., Burlando, M., Freda, A., \& Repetto, M. P. (2018). Large-scale forcing effects on wind flows in the urban canopy: impact of inflow conditions. Sustainable Cities and Society, 42, 593-610. https://doi.org/10.1016/j.scs.2018.08.012

\section{Document license: \\ TAVERNE}

DOI:

10.1016/j.scs.2018.08.012

Document status and date:

Published: 01/10/2018

\section{Document Version:}

Publisher's PDF, also known as Version of Record (includes final page, issue and volume numbers)

\section{Please check the document version of this publication:}

- A submitted manuscript is the version of the article upon submission and before peer-review. There can be important differences between the submitted version and the official published version of record. People interested in the research are advised to contact the author for the final version of the publication, or visit the $\mathrm{DOI}$ to the publisher's website.

- The final author version and the galley proof are versions of the publication after peer review.

- The final published version features the final layout of the paper including the volume, issue and page numbers.

Link to publication

\section{General rights}

Copyright and moral rights for the publications made accessible in the public portal are retained by the authors and/or other copyright owners and it is a condition of accessing publications that users recognise and abide by the legal requirements associated with these rights.

- Users may download and print one copy of any publication from the public portal for the purpose of private study or research.

- You may not further distribute the material or use it for any profit-making activity or commercial gain

- You may freely distribute the URL identifying the publication in the public portal.

If the publication is distributed under the terms of Article $25 \mathrm{fa}$ of the Dutch Copyright Act, indicated by the "Taverne" license above, please follow below link for the End User Agreement:

www.tue.nl/taverne

Take down policy

If you believe that this document breaches copyright please contact us at:

openaccess@tue.nl

providing details and we will investigate your claim. 


\title{
Large-scale forcing effects on wind flows in the urban canopy: Impact of inflow conditions
}

\author{
Alessio Ricci $^{\mathrm{a}, \mathrm{b}, \mathrm{c}, *}$, Ivo Kalkman ${ }^{\mathrm{b}}$, Bert Blocken ${ }^{\mathrm{b}, \mathrm{c}}$, Massimiliano Burlando ${ }^{\mathrm{a}}$, Andrea Freda ${ }^{\mathrm{a}}$, \\ Maria Pia Repetto ${ }^{a}$

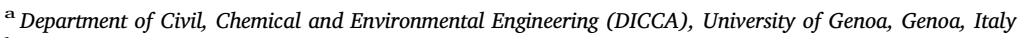 \\ ${ }^{\mathrm{b}}$ Building Physics and Services, Department of the Built Environment, Eindhoven University of Technology, Eindhoven, The Netherlands \\ ${ }^{\mathrm{c}}$ Building Physics Section, Department of Civil Engineering, KU Leuven, Leuven, Belgium
}

\section{A R T I C L E I N F O}

\section{Keywords:}

CFD simulation

RANS

Urban wind flow

Inflow conditions

Statistical performance

\begin{abstract}
A B S T R A C T
Wind flow modeling in urban areas is usually performed by means of Wind-Tunnel (WT) testing or Computational Fluid Dynamics (CFD) simulations. Results obtained with both techniques can be affected by the boundary conditions. This study aims at investigating how two sets of inflow conditions, termed set 1 and set 2 and calculated respectively using the equations proposed by Richards and Hoxey (1993) and Tominaga et al. (2008), may affect the accuracy of the results in terms of mean wind speed, turbulent kinetic energy, yaw and pitch angles when predicting wind flows in urban areas. 3D steady RANS simulations were performed for a selected urban area ("Quartiere La Venezia" in Livorno, Italy). WT tests on the same urban model were used to validate the CFD simulations. Mean wind profiles at 25 positions in the urban area were compared and the statistical performance was quantified using four metrics for both sets of inflow conditions. The results obtained using the two sets of inflow conditions showed comparable performances in terms of wind flow predictions in the urban canopy, which means that at the building scale there is no need to use more accurate conditions because they are as effective as the simpler ones.
\end{abstract}

\section{Introduction}

Many factors affect the accuracyof wind flow modeling in an urban environment: reviews on this topic were provided by e.g. Britter and Hanna (2003), Barlow et al. (2013), Blocken (2018), Fernando (2010) and Fernando et al. (2010). The proper representation of large-scale forcing through the inlet boundary conditions and the local-scale forcing due to urban obstacles (e.g. buildings, bridges and trees) represent only a few of many challenges. Several studies focused on numerical wind flow modeling have been carried out over random urban-like obstacles (e.g. Xie, Coceal, \& Castro, 2008), uniform and staggered building arrays (e.g. An, Fung, \& Yim, 2013; Blocken, Vervoort, \& van Hooff, 2016; Coceal \& Belcher, 2004; Razak, Hagishima, Ikegaya, \& Tanimoto, 2013; Xie \& Castro, 2006), idealized urban surfaces (e.g. Cheng \& Porté-Agel, 2015), semi-idealized urban canopies (e.g. Carpentieri \& Robins, 2015; Hertwig, Efthimiou, Bartzis, \& Leitl, 2012) and actual urban environments (Blocken, Janssen, \& van Hooff, 2012; García Sánchez, Philips, \& Gorlé, 2014; Hanna et al., 2006; Janssen, Blocken, \& van Hooff, 2013). While best practice guidelines contain a maximum blockage ratio that ensures that interaction effects between the sides of the domain (or test section) and the urban model are sufficiently small (ASCE, 2003; Blocken, 2015; Franke, Hellsten, Schlünzen, \& Carissimo, 2007; Tominaga et al., 2008), the choice of inflow conditions is not straightforward. Extensive literature exists on the representation of the atmospheric boundary layer (ABL) in WT tests employing different types of spires, fences and sets of roughness elements (e.g. Counihan, 1969; Irwin, 1980; Kozmar, 2011a, 2011b). Measurements of mean wind velocity, turbulence intensity, spectra and turbulent length scales of different boundary-layer WT setup were compared extensively with actual atmospheric data (Armitt \& Counihan, 1968; Balendra, Shah, Tey, \& Kong, 2002; Cermak, 1972; Counihan, 1969, 1970; Farell \& Iyengar, 1999; Kozmar, 2010; Lloyd, 1967; Plate, 1982, 1999). As stressed by Counihan $(1969,1970)$, who tried to simulate a neutral ABL in a boundary-layer WT, spanwise uniformity of ABL flow, upstream of the turntable (where the WT model is usually placed), is an essential requirement. However, non-uniformity in the spanwise direction may occur during WT tests (Counihan, 1970) in terms of both mean wind velocity $U(z)$ and

\footnotetext{
* Corresponding author.

E-mail addresses: alessio.ricci@unige.it, a.ricci@tue.nl, alessio.ricci@kuleuven.be (A. Ricci), ivokalkman@hotmail.com (I. Kalkman), b.j.e.blocken@tue.nl,

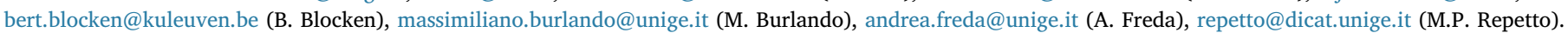


turbulence intensity $I(z)$ profiles. This is likely caused by the limited length of the WT test section combined with the fetch of roughness and the spires employed to generate the ABL profile (Counihan, 1970). Nonuniform inflow conditions can induce uncertainties in the WT results (e.g. mean velocity, turbulence intensity, pressure coefficient values) the extent of which has not yet been fully analyzed.

In the past decades, much work has been performed on the reproduction of WT tests by CFD simulations in order to improve the performance and to better understand the strengths and weaknesses of both techniques (Baker, 2007; Blocken, 2014, 2015; Meroney, 2016; Murakami, 1990; Stathopoulos, 1997; Tominaga \& Stathopoulos, 2013).

As proposed by Moonen, Blocken, and Roels (2006), the inflow conditions can be directly reproduced by modeling the entire WT in CFD including the corner guide vanes, the diffuser and the contraction as part of the computational domain. However, this approach entails a very high computational cost. The more common and less expensive technique, widely adopted in urban physics and wind engineering applications, consists of reproducing (only a portion of) the WT test section. In this technique, as far as 3D steady-state RANS simulations are concerned, the mean wind velocity $(U)$, turbulent kinetic energy $(k)$ and the turbulence dissipation rate $(\varepsilon)$ or specific dissipation rate $(\omega)$ profiles are imposed at the inlet face of the computational domain. Such a domain inlet face generally coincides with a measuring position located upstream of the turntable in the WT section. Two options are then available. The first option consists of reproducing the profiles in terms of mean velocity $(U)$, turbulent kinetic energy $(k)$ and turbulence dissipation rate $(\varepsilon)$ using the data $\left(U, \sigma_{u}(z), \sigma_{v}(z)\right.$ and $\left.\sigma_{w}(z)\right)$ measured somewhere in the WT section upstream of the turntable. In this case, the turbulent kinetic energy $(k)$ and the turbulence dissipation rate $(\varepsilon)$ profiles are commonly calculated using a set of two equations proposed by Tominaga et al. (2008). The second option consists of fitting the aforementioned measured mean velocity data (in the WT section) to a logarithmic law and use the friction velocity $\left(u^{*}\right)$ and roughness length $\left(z_{0}\right)$ values derived from the fit to calculate the turbulent kinetic energy $(k)$ and turbulence dissipation rate $(\varepsilon)$ profiles. In this case, a set of two equations proposed by Richards and Hoxey (1993) is commonly employed. Both sets of equations, i.e. Richards and Hoxey (1993) and Tominaga et al. (2008), are reported and described in Section 3.2.

At present, it is not clear how the choice of one these two options affects the CFD results in terms of mean velocity and turbulent kinetic energy profiles, yaw and pitch angles. Weerasuriya et al. (2018) adopted different CFD codes to simulate twisted wind flows effects on buildings, showing large differences in wind speeds in the downstream zone, compared to those measured in the WT tests (Tse, Weerasuriya, Zhang, Li, \& Kwok, 2017).

The present contribution is part of a larger research project (Repetto, Burlando, Solari, De Gaetano, \& Pizzo, 2017; Repetto, Burlando, Solari, De Gaetano, Pizzo, Tizzi, 2017) aimed at quantifying the impact of CFD parameters (geometrical simplifications, inflow conditions, turbulence models, numerical approach, etc.) on RANS simulation results of wind flow over a historical urban area. For this purpose, a neighborhood of Livorno city (Italy), the so-called Quartiere La Venezia, is selected as a case study. There are two reasons for choosing this area. The former is due to its urban morphology, which is representative of many historical districts of Mediterranean cities. The latter is that the wind flow in the Port of Livorno is monitored by a network of instruments made available within the framework of the European projects "Wind and Ports" and "Wind, Ports, and Sea" (Burlando, Tizzi, \& Solari, 2017; Repetto, Burlando, Solari, De Gaetano, Pizzo, 2017; Repetto, Burlando, Solari, De Gaetano, Pizzo, Tizzi, 2017; Solari et al., 2012). In a previous step, WT tests were performed on a reduced-scale urban model (1:300) (Ricci, Burlando, Freda, \& Repetto, 2017). The present paper deals with 3D steady-state RANS simulations employing the realizable $k-\varepsilon$ turbulence model and two sets of inflow profiles (i.e. set 1 and set 2) applied to the reduced-scale urban model (corresponding to the one used in WT tests) by reproducing a portion of the WT test section. The numerical results, in terms of mean wind velocity, turbulent kinetic energy, yaw and pitch angles are compared with the WT results. Finally, four validation metrics are used to quantify the deviations of the CFD results from the WT results, in terms of mean velocity, turbulent kinetic energy and yaw and pitch angles, caused by the inflow profiles.

The paper is organized as follows. Section 2 contains a short description of the urban model and the experimental setup. In Section 3 the computational settings and parameters are described: the computational geometry, domain and grid, the inflow conditions, the other boundary conditions and the solver settings. Section 4 presents the comparison of the WT and CFD results in terms of mean wind velocity and turbulent kinetic energy profiles, yaw and pitch angles. In Section 5 the agreement between WT and CFD results is quantified using validation metrics. Finally, Section 6 concludes the paper with discussions and conclusions.

\section{Description of experimental setup}

The studied urban district Quartiere La Venezia was reproduced at a reduced scale of 1:300 (Fig. 1). WT tests of wind flow over this urban area were performed at the Department of Civil, Chemical and Environmental Engineering (DICCA) of the University of Genoa (Italy) using a closed-loop subsonic wind tunnel for aerodynamics and civil experiments with a cross section of $1.70 \times 1.35 \mathrm{~m}^{2}$ (width $\mathrm{x}$ height). WT tests were carried out for three incoming wind directions (i.e. $\alpha=240^{\circ}, 270^{\circ}, 300^{\circ}$ ) corresponding to the prevalent ones for the strongest winds in Livorno (Ricci, Burlando et al., 2017). The blockage ratio was kept below $3.5 \%$ for all wind directions considered. The windflow pattern inside the urban area was monitored at 25 measuring positions and 15 heights (from 0.02 to $0.6 \mathrm{~m}$ above the tunnel floor) as shown in Fig. 2(a-b). In particular, two sets of positions were used: the positions $\left(\mathrm{L} 1_{1-5}, \mathrm{~L} 2_{1-5}, \mathrm{~L} 3_{1-5}\right)$ consisting of a grid of 15 points with the same local reference system as the WT section (Fig. 2a), and ten positions $\left(\mathrm{A} 1_{1}-\mathrm{A} 5_{2}\right)$ fixed to the urban model and placed along "Canale
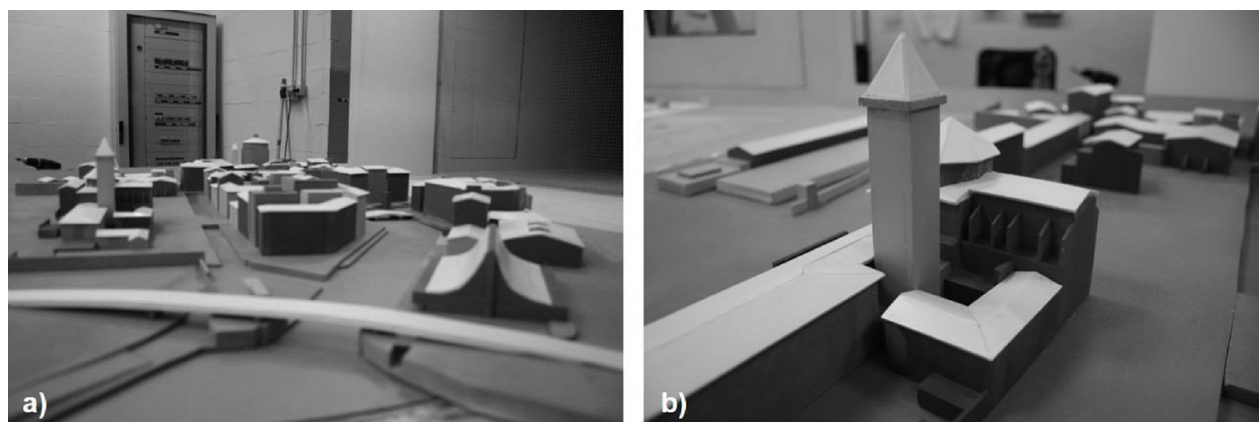

Fig. 1. WT model: (a) overview of Quartiere La Venezia and (b) detailed view of Piazza Luogo Pio. 

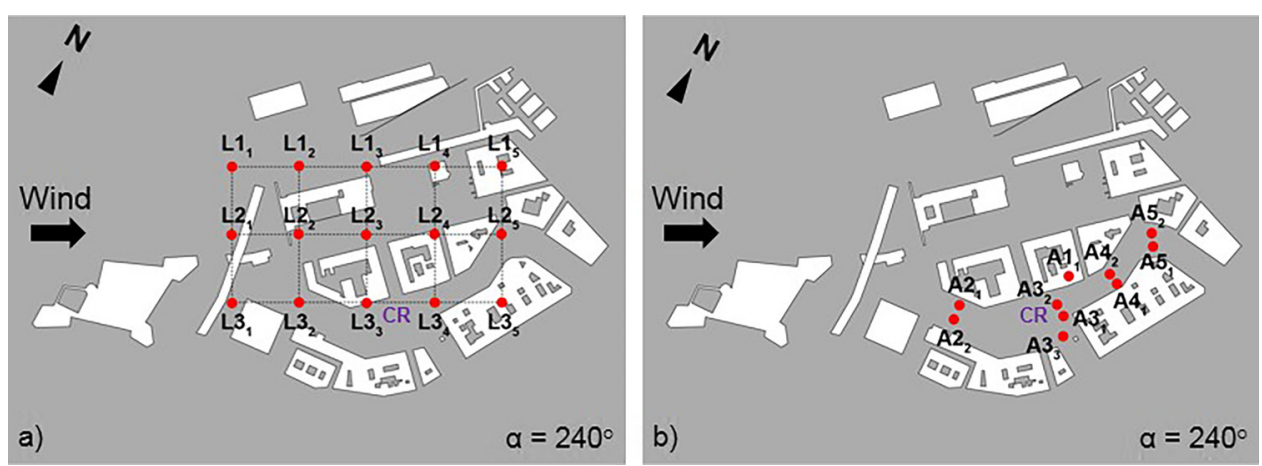

Fig. 2. Location of measurement positions (a) $\left(\mathrm{L} 1_{1-5}, \mathrm{~L} 2_{1-5}, \mathrm{~L} 3_{1-5}\right)$ and (b) $\left(\mathrm{A} 1_{1}-\mathrm{A} 5_{2}\right)$ in the investigated district of Livorno city. Canale Rosciano is indicated by "CR" in the figures.

Rosciano" (Fig. 2b). Spires, fences and roughness cubes of various dimensions (i.e. $6 \times 6,3 \times 3$ and $2 \times 2 \mathrm{~cm}^{2}$ ) were used in order to reproduce the neutral ABL in the WT section. For more details the reader is referred to Ricci, Burlando et al. (2017).

\section{CFD simulations: computational settings and parameters}

\subsection{Computational geometry, domain and grid}

CFD simulations were performed on the reduced-scale urban model (1:300) of Quartiere La Venezia for the same incoming wind directions as the WT tests. The size of the domain was $L \times W \times H=5.5 \times 1.70 \times 1.35 \mathrm{~m}^{3}$, where the width $(W)$ and the height $(H)$ were consistent with the cross section of the WT, and the length $(L)$ was equal to the distance occurring between a plane taken $1 \mathrm{~m}$ upstream of the turntable to measure the approach-flow profiles and the safety screen grid mounted at the downstream end of the WT test section. As recommended by Blocken (2015), the vertical blockage ratio $B R_{H}$ (ideally $\leq 17 \%$ ), the lateral blockage ratio $B R_{L}$ (ideally $\leq 17 \%$ ) and the frontal area blockage ratio $B R$ (ideal value $\leq 3 \%$ ) were calculated using the following equations:

$B R=\frac{A_{\text {building }}}{A_{\text {domain }}} \quad B R_{H}=\frac{H_{\text {building }}}{H_{\text {domain }}} \quad B R_{L}=\frac{L_{\text {building }}}{L_{\text {domain }}}$

where $A_{\text {building, }}, H_{\text {building }}$ and $L_{\text {building }}$ are the projected frontal area, the height and the length of the obstacles, respectively. The same quantities indicated by $A_{\text {domain }}, H_{\text {domain }}$ and $L_{\text {domain }}$ refer conversely to the cross section of the computational domain.

While the vertical blockage ratio $B R_{H}=5.8 \%$ was well below the recommended threshold, the lateral $\left(B R_{L}\right)$ and frontal $(B R)$ blockage ratio values (equal to $58.8 \%$ and $3.5 \%$ respectively) were higher than recommended. Nevertheless, the projected frontal area does not take into account that the urban model also consists of streets, canals and open squares through which the wind is free to flow. For this reason, the frontal blockage ratio should be considered a rather pessimistic indicator for the present geometry. Moreover, it is worth to note that the effect of the side walls on the measurements can be expected to be quite limited, since all the measuring positions (A and L) were located in the central part of the district and at $0.625 \mathrm{~m}$ from the side walls.

In an earlier publication (Ricci, Kalkman et al., 2017) two geometries (so-called simplified and approximated geometrical models) of the urban district Quartiere La Venezia with different degrees of precision were generated by Gambit 2.4.6 in order to quantify the impact of geometrical simplifications. According to the results obtained in that study, the best performing geometry (the approximated model) was chosen for further analyses in the present paper. In order to correctly reproduce the inflow conditions of the WT tests, the inlet face of the computational domain was placed where the approach-flow profiles were measured in the WT (i.e. $1 \mathrm{~m}$ upstream of the first building of the urban model). For each considered wind direction, a separate grid was constructed using the surface-grid extrusion technique proposed by van Hooff and Blocken (2010) in order to achieve a high-level control over the whole computational grid and adhering to the best practice guidelines (Blocken, 2015; Franke et al., 2007; Tominaga et al., 2008). The same or a higher grid resolution than adopted in the previous studies based on grid-sensitivity analysis (Blocken et al., 2012; van Hooff \& Blocken, 2010) was used and all the building edges were discretized with at least thirty cells, which is three times larger the minimum number (ten) suggested in the best practice guidelines by Franke et al. (2007) and Tominaga et al. (2008). Fig. 3 shows the computational grids generated for each wind direction. The resulting grids counted 23.2 million cells for $\alpha=240^{\circ}, 20.8$ million cells for $\alpha=270^{\circ}$, and 19.9 million cells for $\alpha=300^{\circ}$. Fully hexahedral meshes with increased resolution close to the walls (of buildings, bridges and ground level) were used in order to maximize the numerical accuracy, limit numerical diffusion and avoid convergence problems (Blocken et al., 2012).

\subsection{Inflow conditions}

Two commonly adopted sets of inflow conditions were used in the present study. The first set, termed set 1 , consisted of the mean wind velocity $U(z)$ profiles and the turbulent kinetic energy $k(z)$ and turbulence dissipation rate $\varepsilon(z)$ profiles calculated from the velocity standard deviations $\sigma_{u}(z), \sigma_{v}(z), \sigma_{w}(z)$ as measured in the WT. The profiles were measured along three vertical lines (L1, L2, L3) (Fig. 4). Line L2 was located at the central axis of the cross section and the distance with respect to L1 and L3 was of $0.25 \mathrm{~m}(a)$. The height of the WT cross section $(H=1.35 \mathrm{~m})$ was assumed as reference height $\left(z_{r e f}\right)$ (Fig. 4). Lines L1 and L3 are placed at $0.6 \mathrm{~m}(b)$ from the side walls of the WT (Fig. 4). The three lines were chosen $1 \mathrm{~m}(d)$ upstream of the first building of the urban model, and in correspondence of the lines $\mathrm{L} 1_{1-5}$ $\mathrm{L} 2_{1-5}$ and $\mathrm{L} 3_{1-5}$ previously introduced in Fig. $2 \mathrm{a}$. Due to the limitations in the movement of the traverse system, the ABL profiles (i.e. mean velocities and standard deviations of the velocity fluctuations) were measured along each line (i.e. L1, L2 and L3) at 15 different heights between 0 and $0.44 z / z_{\text {ref }}$ (i.e. from 0.02 to $0.60 \mathrm{~m}$ ), using a multihole pressure probe (Fig. 4). Next, in order to determine the boundary layer (BL) thickness near the top wall of the WT, mean wind velocities and standard deviations of the velocities fluctuations were measured at 8 different heights between 0.9 and $1.0 z / z_{\text {ref }}$ along each line (i.e. L1, L2 and L3) using a boundary-layer rake (Barlow, Rae, \& Pope, 1999) (Fig. 4). In the remaining range $0.44-0.9 z / z_{\text {ref }}$, mean velocity values and velocity standard deviations were linearly interpolated (between corresponding positions: A1 - B1, A2 - B2, and A3 - B3) in order to link both measured parts (Fig. 4). Overall, different mean wind velocity profiles were found along the three lines (L1, L2, L3) indicating a nonuniformity of the ABL flow in the spanwise direction upstream of the 


\section{a)}

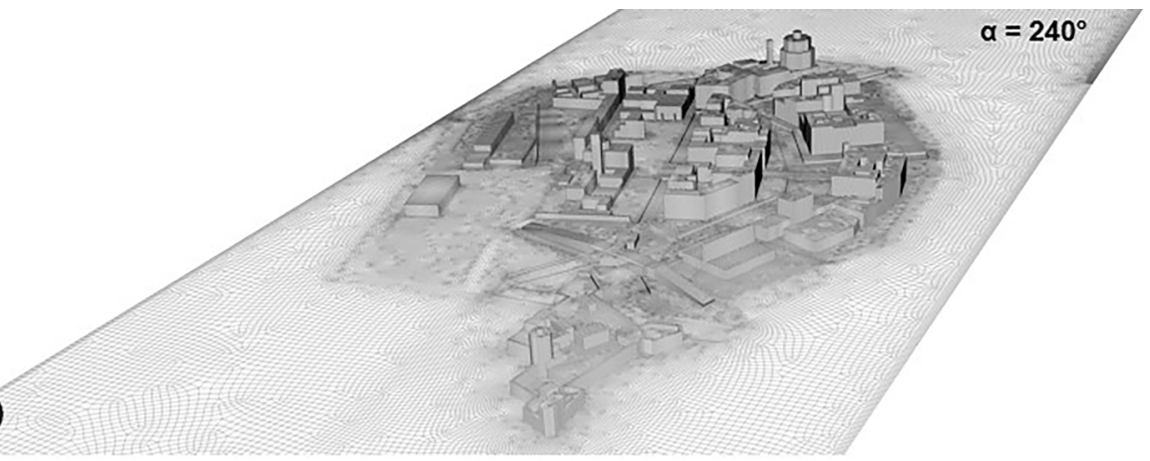

b)

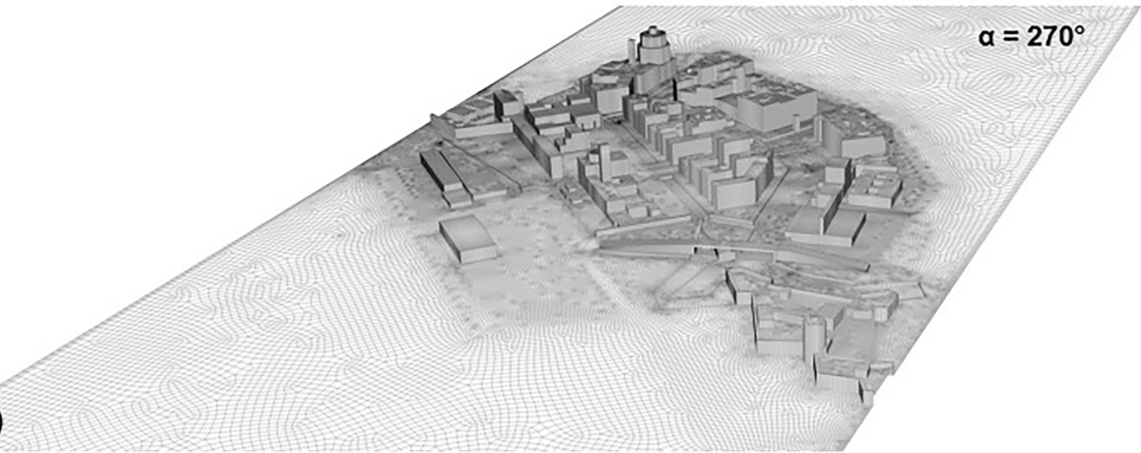

c)

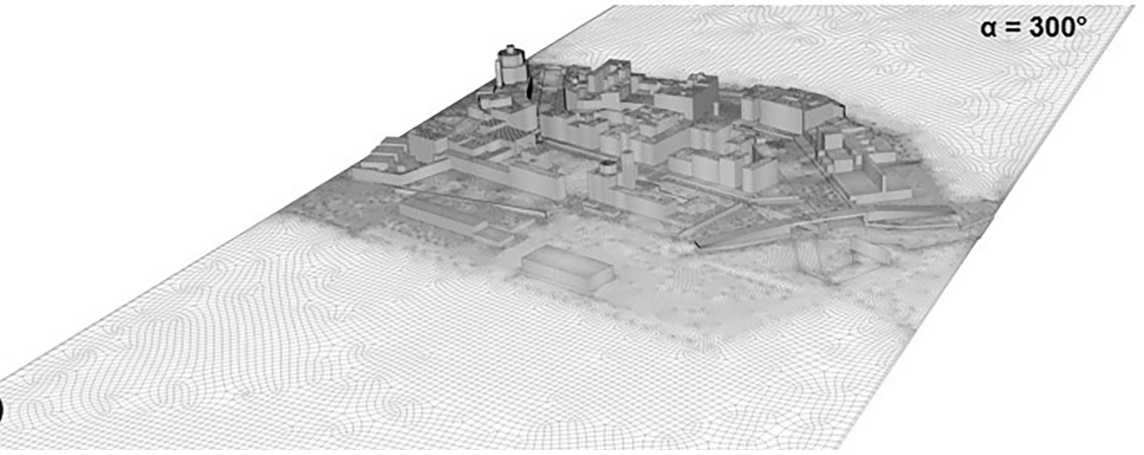

Fig. 3. Perspective view of the three computational grids: (a) wind direction $\alpha=240^{\circ}$, (b) wind direction $\alpha=270^{\circ}$, (c) wind direction $\alpha=300^{\circ}$.

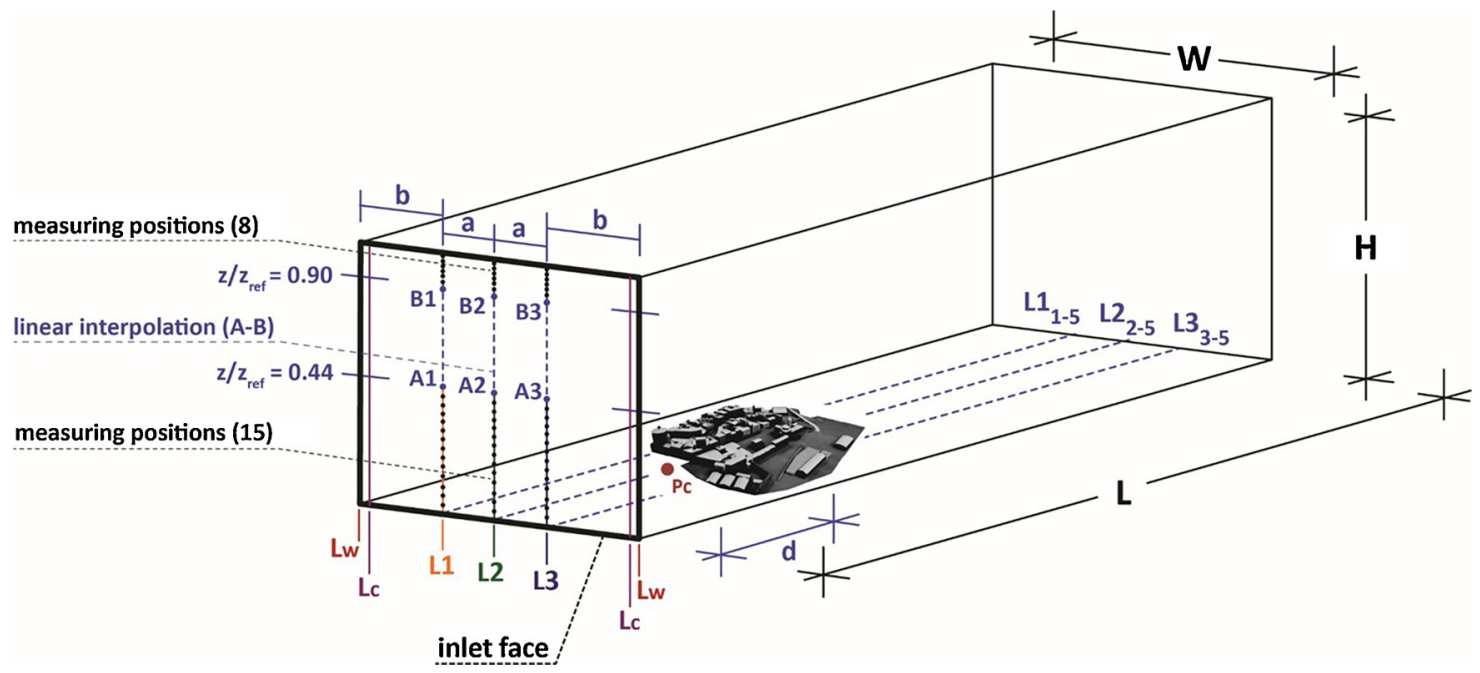

Fig. 4. The computational domain with size $L \times W \times H=5.5 \times 1.70 \times 1.35 \mathrm{~m}^{3}$. The black dots along the three vertical lines (L1, L2 and L3) are the positions chosen for the WT tests to measure the mean velocity and standard deviations of the velocity fluctuations. The lines indicated by $\mathrm{L}_{\mathrm{c}}$ correspond to the positions of the centroid of the second cells (of the inlet face) starting from the lateral edges in turn indicated by $\mathrm{L}_{\mathrm{w}}$. The distances indicated by " $a$ ", " $b$ " and " $d$ " are equal to $0.25 \mathrm{~m}$, $0.60 \mathrm{~m}$ and $1 \mathrm{~m}$, respectively. 

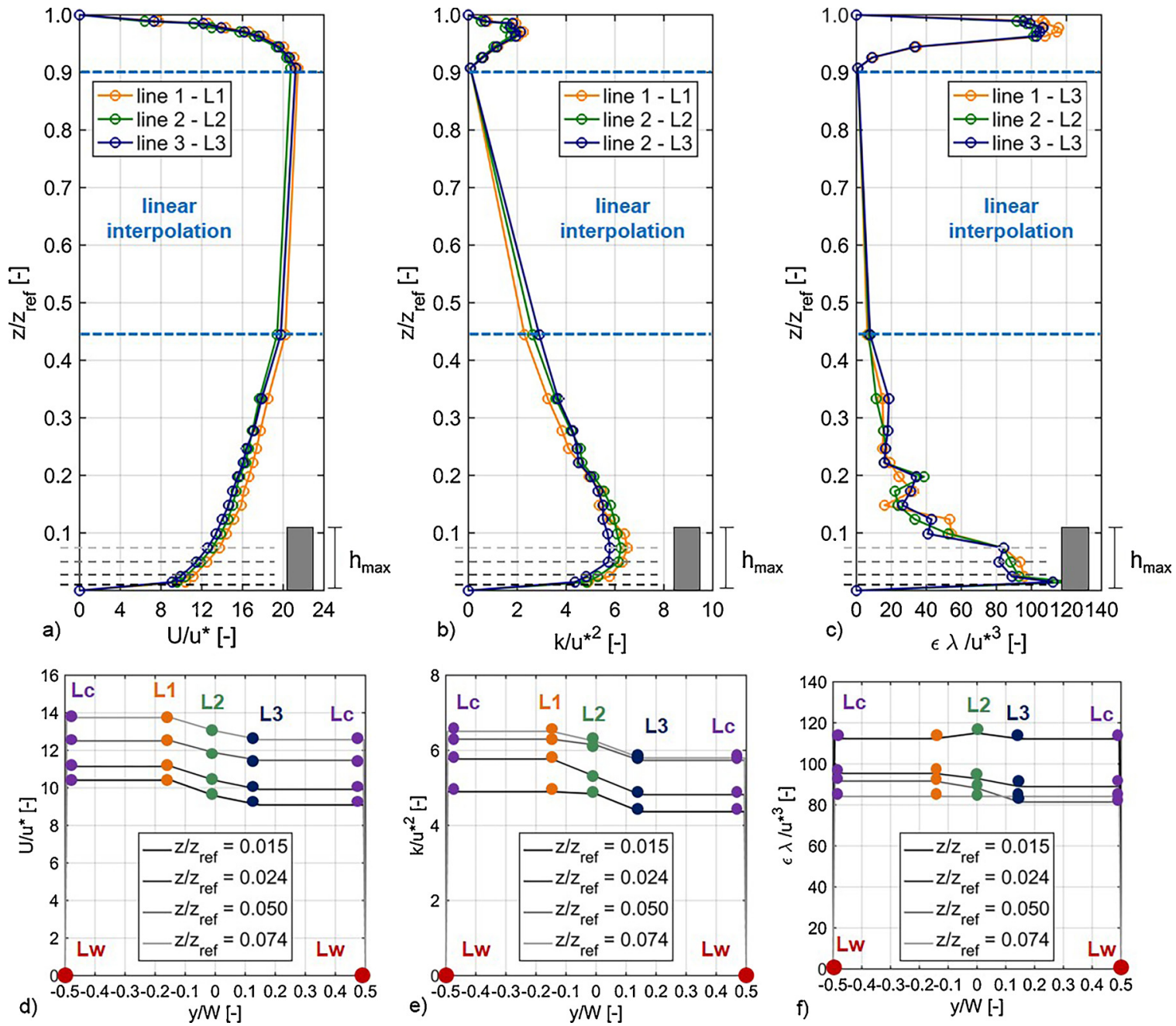

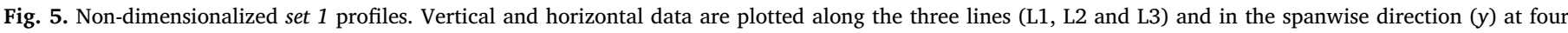

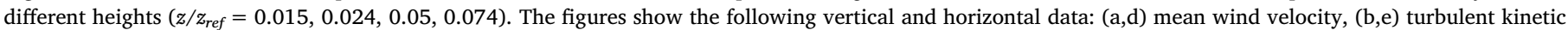
energy and (c,f) turbulence dissipation rate. The height of the tallest building $\left(h_{\max }=0.15 \mathrm{~m}\right)$ is indicated by the gray rectangle in the subfigures (a,b,c).

turntable (Fig. 5a). This non-uniformity was also found in the turbulent kinetic energy $k(z)$ and turbulence dissipation rate $\varepsilon(z)$ profiles that were calculated using the WT measurements (i.e. $U, \sigma_{u}(z), \sigma_{v}(z)$ and $\left.\sigma_{w}(z)\right)$ and the equations proposed by Tominaga et al. (2008):

$k(z)=\frac{1}{2}\left(\sigma_{u}^{2}(z)+\sigma_{v}^{2}(z)+\sigma_{w}^{2}(z)\right)$

$\varepsilon(z)=C_{\mu}^{1 / 2} k(z) \frac{d U}{d z}$

where $C_{\mu}$ is a constant equal to 0.09 . Mean wind velocity ( $U$ ), turbulent kinetic energy $(k)$ and turbulence dissipation rate $\varepsilon(z)$ profiles were imposed (as inflow conditions) at the inlet face of the computational domain (Fig. 4). At the inlet face, the values of $U, k$ and $\varepsilon$ were linearly interpolated using the known values measured at the 23 positions (i.e. 15 in the lower part and 8 in the higher part) taken on each lines (L1, $\mathrm{L} 2, \mathrm{~L} 3$ ) and kept constant in the range $\mathrm{L}_{\mathrm{c}}-\mathrm{L} 1$ and $\mathrm{L} 3-\mathrm{L}_{\mathrm{c}}$, where $\mathrm{L}_{\mathrm{c}}$ corresponds to the vertical line taken in correspondence of the centroid of second cell starting from the lateral edges $\left(\mathrm{L}_{\mathrm{w}}\right)$ (Fig. 4). The linear interpolation was performed between the centroid of two contiguous cells of the entire inlet face using the function of the open-source program used to perform the CFD simulations (OpenFOAM 2.3.0). The nonuniformity of profiles in the spanwise direction $(W)$ is further clarified by Fig. 5(d-f), where the value of $U, k$ and $\varepsilon$ at different heights (at $0.015,0.024,0.050$ and $0.074 z / z_{\text {ref }}$ above the tunnel floor) along different vertical lines are plotted as an example. The profiles and values in Fig. 5 were non-dimensionalized with the friction velocity value $\left(u^{*}=0.89 \mathrm{~m} / \mathrm{s}\right)$, the square of the friction velocity $\left(u^{*}\right)$, and the fraction $u^{* 3} / \lambda$, respectively, where $\lambda$ represents a characteristic length scale which was taken equal to the height $(H=1.35 \mathrm{~m})$ of the computational domain. The aforementioned friction velocity value $(0.89 \mathrm{~m} /$ s) was obtained by fitting the profile between 0 and $0.44 z / z_{\text {ref }}$ obtained in turn by spanwise averaging of the three mean velocity profiles (L1, L2, L3). Due to the non-uniformity of the ABL profile in the spanwise direction and to the non-perfect logarithmic distribution of the measured data between 0 and $0.44 z / z_{\text {ref }}$, the latter step was essential in order to obtain only one representative friction velocity value of the ABL profile by which non-dimensionalize both of sets of inflow profiles of Figs. 5 and 6.

In the second set of inflow conditions, referred to as set 2 , as aforementioned the mean velocity inflow profile was obtained by fitting the profile, obtained in turn by spanwise averaging of the three mean velocity profiles (L1, L2, L3) previously described (see Fig. 5a), to a logarithmic law:

$U(z)=\frac{u^{*}}{\kappa} \ln \left(\frac{z}{z_{0}}\right)$

where $\kappa$ indicates the von Karman constant taken equal to 0.41 . The fit was realized only in the range $0-0.44 z / z_{\text {ref }}$ (above the WT floor) (Fig. 6a), yielding $u^{*}=0.89 \mathrm{~m} / \mathrm{s}$ and $z_{0}=0.11 \mathrm{~m}$ in Eq. (3). In the range 0.9 and $1.0 z / z_{\text {ref }}$ the profile was obtained by averaging the three 

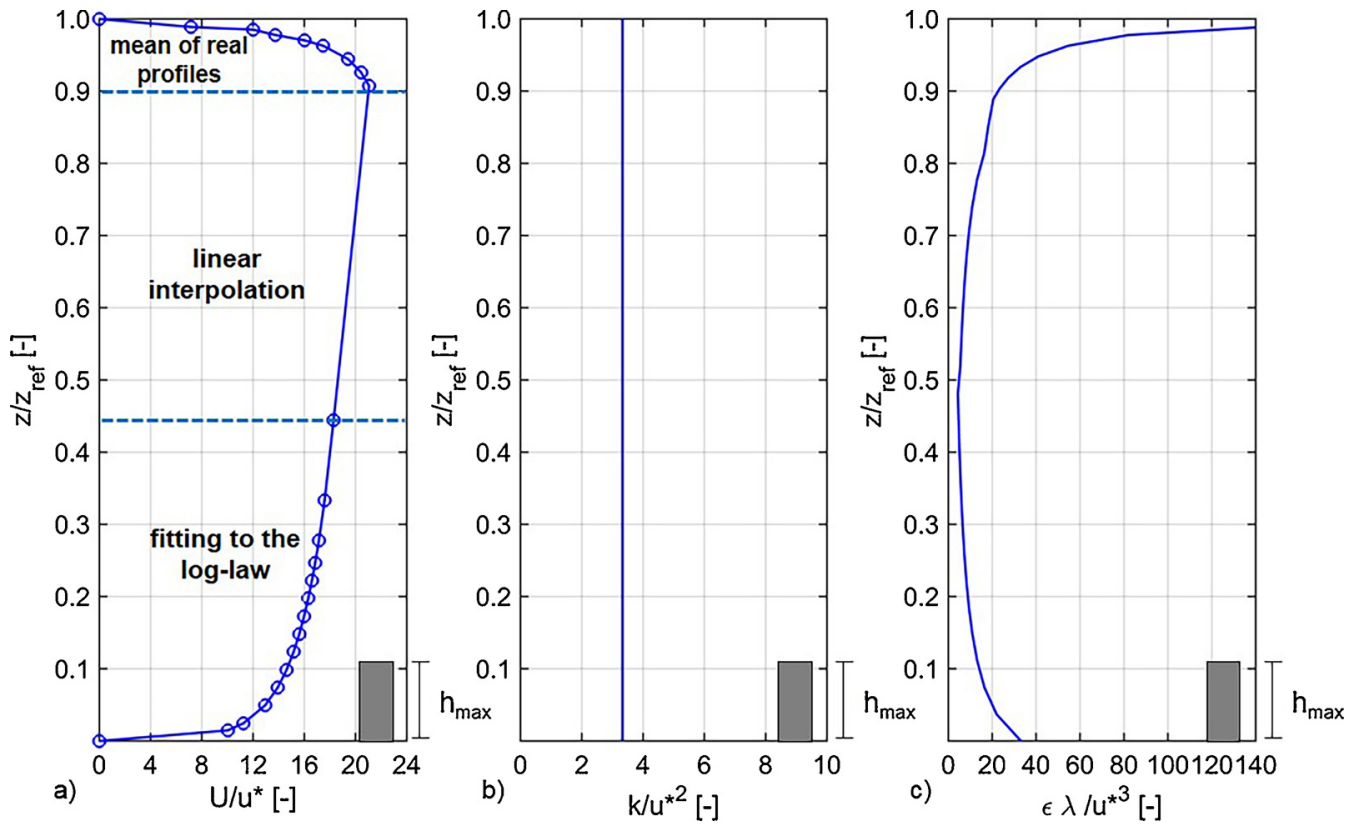

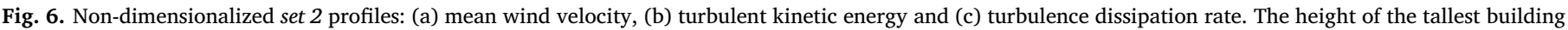
$\left(h_{\max }=0.15 \mathrm{~m}\right)$ is indicated by the gray rectangle in the subfigures $(\mathrm{a}-\mathrm{c})$.

mean velocity profiles (L1, L2, L3) measured by a boundary-layer rake (as above described) (Fig. 6a). In the range 0.44-0.9 z/z ref, the mean velocity and the standard deviations of the turbulent fluctuations were linearly interpolated in order to link both parts, as done for the first set of inflow profiles (Fig. 6a). The turbulent kinetic energy $k$ and the turbulence dissipation rate $\varepsilon(z)$ were calculated as proposed by Richards and Hoxey (1993) (Fig. 6b-c):

$k=\frac{u^{* 2}}{\sqrt{C_{\mu}}}$

$\varepsilon(z)=\frac{u^{* 3}}{\kappa\left(z+z_{0}\right)}$

The profiles are shown in Fig. 6. They were non-dimensionalized with respect to the same values $\left(u^{*}\right.$ and $\lambda$ ) used for the set 1 . The profiles of $U, k$ and $\varepsilon$ were imposed on the inlet face of the computational domain using the same procedure adopted for the set 1 .

The relative difference found, between set 1 (considering the mean value obtained among the three values at lines L1, L2 and L3) and set 2, in terms of mean velocity value was equal to $4.42 \%$ at $0.033 \mathrm{~m} \mathrm{of} z / z_{\text {ref }}$.

\subsection{Other boundary conditions and solver settings}

Other boundary conditions were also defined in order to reproduce the WT experimental conditions. The size of the first near-wall cell (i.e. equal to $0.0033 \mathrm{~m}$ ) was chosen to obtain dimensionless wall unit values $y^{+}$(i.e. $y_{\text {avg }}^{+}=101.20$ ) in the logarithmic layer range, i.e. $30-300$ (Blocken, Stathopoulos, \& Carmeliet, 2007; Blocken, Carmeliet, \& Stathopoulos, 2007). The equivalent sand-grain roughness height $k_{s}$ was calculated according to Blocken, Stathopoulos et al. (2007) as $k_{s}=9.793 z_{0} / C_{s}$. In this equation the roughness constant, $C_{s}$, was taken equal to 2.5 in order to comply with the necessary condition $y_{p}>k_{s}$, where $y_{p}$ is the distance between the center point of wall-adjacent cell and the wall. At the bottom, sides and top of the domain the standard wall functions proposed by Launder and Spalding (1974) with roughness modification by Cebeci and Bradshaw (1977) were used. In that regard, the so-called epsilonWallFunction, kqRWallFunction, nutkRoughWallFunction and nutkWallFunction were used to solve the turbulence dissipation rate $(\varepsilon)$, the turbulent kinetic energy $(k)$, the turbulence viscosity $(\nu)$ both for the rough and slip wall conditions, respectively. At the bottom an equivalent sand-grain roughness height $k_{s}$ equal to $0.0013 \mathrm{~m}$ was imposed. At the sides and top of the computational domain as well as on the obstacles explicitly modeled (e.g. building and bridge surfaces), $k_{s}$ was chosen equal to zero. Finally, a zero static gauge pressure was applied at the outlet face (Fig. 7).

All the simulations were performed using the 3D steady-state RANS approach and the realizable $k-\varepsilon$ turbulence model (Shih, Liou, Shabbir, \& Zhu, 1995). Second-order discretization schemes for the governing equations and the SIMPLE algorithm for pressure-velocity coupling were used (Ferziger \& Perić, 2002; Patankar, 1980; Versteeg \& Malalasekera, 2007). Convergence was reached when the residuals showed negligible fluctuations during the iterative process. The following minimum values of residuals were found for all CFD simulations performed: $10^{-8}$ for the three mean velocity components, $10^{-7}$ for the turbulent kinetic energy $(k)$ and turbulence dissipation rate $(\varepsilon)$ and $10^{-6}$ for continuity. All CFD simulations were carried out using the open-source CFD package OpenFOAM 2.3.0 and the cluster of the Department of Civil, Chemical and Environmental Engineering of the University of Genoa (Italy) using 32 cores of AMD Opteron ${ }^{\mathrm{TM}}$ processors running at $1.4 \mathrm{GHz}$. Each simulation required approximately 190-200 wall-clock-hours.

\section{CFD simulations: results}

\subsection{Mean wind velocity contours}

Contours of dimensionless mean wind velocity of the two CFD cases, termed set 1 case and set 2 case, for the three incoming wind directions, made at $0.033 z / z_{\text {ref }}$ (corresponding to $0.02 \mathrm{~m}$ above the bottom - the first measuring level considered during the WT tests) are presented in Fig. 8. The reference height $\left(z_{r e f}\right)$ corresponds to the highest point, measured by the traverse system and the multihole pressure probe, located at $0.60 \mathrm{~m}$ above the tunnel floor. All the contours were nondimensionalized with respect to the friction velocity value at the inlet, $u^{*}=0.89 \mathrm{~m} / \mathrm{s}$. In general, the contours showed small differences between the set 1 and the set 2 cases for the three wind directions analyzed.

For the wind direction $\alpha=240^{\circ}$ the set 1 case showed higher wind velocity ratios $\left(U / u^{*}\right)$ than the set 2 case mostly upstream of the urban 


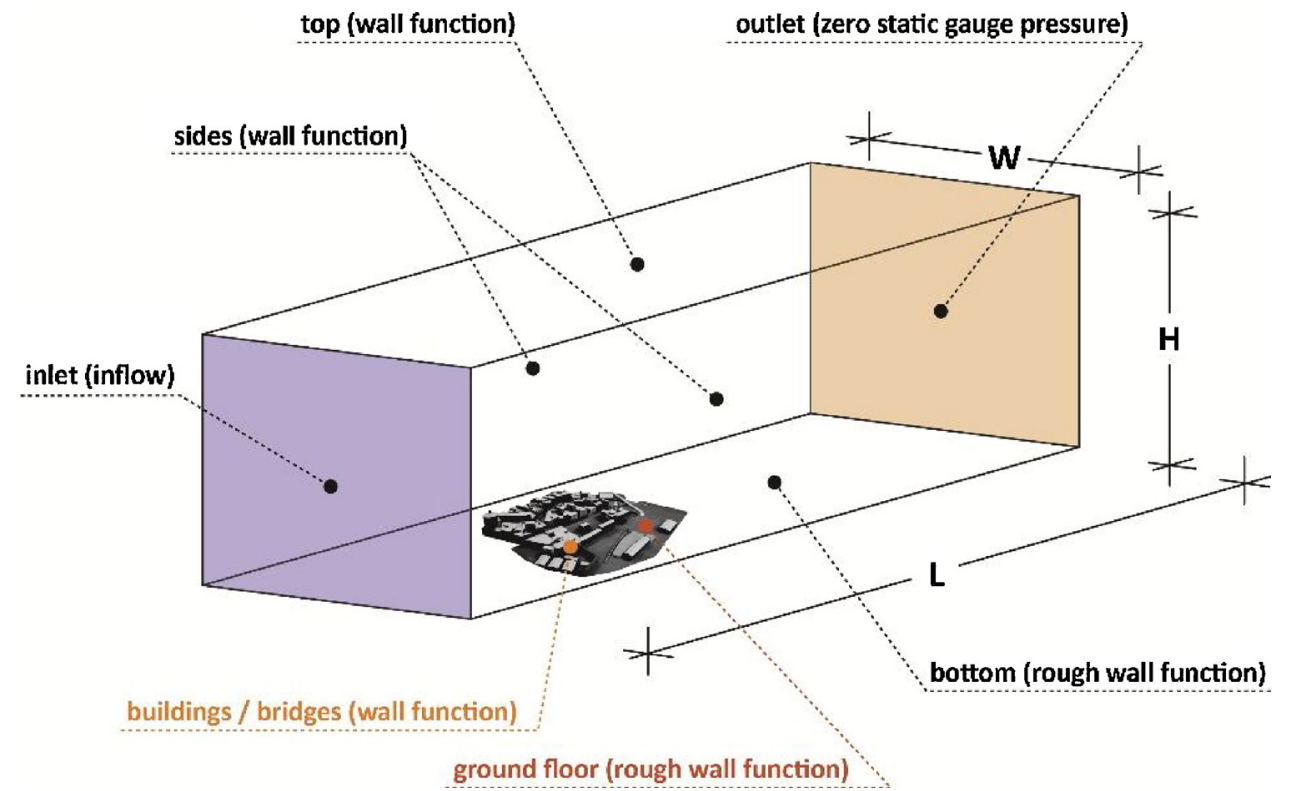

Fig. 7. Boundary conditions of the computational domain.

model, between the inlet face and the first building of the urban model. In contrast a comparable wind-flow pattern of both CFD cases was found along Canale Rosciano (Fig. 8a-b). For this incoming wind direction $\left(\alpha=240^{\circ}\right)$ the approach-flow was almost aligned with the entrance of Canale Rosciano and the mean wind velocity at this height (i.e. at $0.033 z / z_{\text {ref }}$ ) was reduced by the ancient fortress of Livorno called "Fortezza Antica" and the bridge of "Viale della Cinta Esterna" (indicated in the figures by " $F$ " and "bridge" respectively).

For the wind direction $\alpha=270^{\circ}$ approximately the same mean velocity fields both outside the urban area and along Canale Rosciano were observed for both CFD cases (Fig. 8c-d).

For the wind direction $\alpha=300^{\circ}$ two areas with high mean wind velocity ratio $\left(U / u^{*}\right)$ were found for both $C F D$ cases: the first located at the entrance of Canale Rosciano and the second located close to the right side wall of the computational domain. The latter was probably caused by the interaction between the right side wall of the computational domain and the urban model edges. A higher mean wind velocity ratio for the set 2 case compared with the set 1 case was found in those zones (Fig. 8e-f).

\subsection{Vertical profiles of mean wind velocity}

The horizontal homogeneity of the mean wind velocity profiles, between the inlet face and the position of the first building of the urban model, was investigated in an empty domain having the same dimensions of the one including the urban district. The mean velocity profiles, for both the sets of inflow conditions, were monitored along the line $\mathrm{L} 2_{2-5}$ (see Fig. 2a), between the inlet face and the position where the urban model started (point $P_{c}$ in Fig. 4) at 0.033 of $z / z_{\text {ref }}$ (i.e. at $0.02 \mathrm{~m}$ above the bottom). Relative differences of $0.91 \%$ and $1.62 \%$ (with an increasing of the mean wind velocity) were found at point $P_{c}$ between the mean velocity values of set 1 case and set 2 case, respectively, and their respective inflow values measured at the inlet face at the same height (i.e. at 0.033 of $z / z_{\text {ref }}$ ).

In order to better understand the wind-flow pattern inside Canale Rosciano, the mean wind velocity profiles measured at the positions $\mathrm{A} 2{ }_{2}-\mathrm{A} 5_{2}$ (see Fig. 2) and 15 different levels from 0.02 and $0.6 \mathrm{~m}$ above the bottom during the WT tests and CFD simulations were compared the three wind directions analyzed.

In general, a satisfactory agreement between CFD and WT cases was found in terms of mean velocity profiles for $\alpha=240^{\circ}$. In contrast, for $\alpha=270^{\circ}$ and $\alpha=300^{\circ}$, where more extensive leeward zones were present along Canale Rosciano, the agreement between CFD and WT results deteriorated. The inflow mean velocity profiles of both CFD cases are also reported in Fig. 9 and are indicated by orange (IN set 1 case) and blue (IN set 2 case) dashed lines, respectively. A progressive reduction in terms of mean wind velocity, with respect to the inlet values, was observed along Canale Rosciano from position $\mathrm{A} 2_{2}$ to $\mathrm{A} 5_{2}$ between 0.033 and 0.25 of $z / z_{\text {ref }}$. This aspect will be further discussed in Section 4.3 .

For $\alpha=240^{\circ}$ (Fig. 9a) the difference in mean wind velocity, between both CFD cases, was approximately constant for the four positions (from $\mathrm{A} 2_{2}$ to $\mathrm{A} 5_{2}$ ). At positions $\mathrm{A} 2_{2}$ and $\mathrm{A} 3_{2}$ the set 2 case showed an overestimation in terms of wind velocity values between 0.033 and $0.75 z / z_{\text {ref }}$ compared to the set 1 and WT cases. At positions A4 $4_{2}$ and $\mathrm{A} 5_{2}$ the gap previously observed at positions $\mathrm{A} 2_{2}$ and $\mathrm{A} 3_{2}$ between the two CFD cases was reduced, especially in the lower part of the profiles between about 0.1 and $0.2 z / z_{\text {ref }}$. However, an overestimation of CFD results compared to WT results was still present at the position $\mathrm{A}_{2}$ between 0.033 and 0.75 of $z / z_{\text {ref }}$ except for the level $z / z_{\text {ref }}=0.1$ where the three values were almost coincident.

For $\alpha=270^{\circ}$ (Fig. 9b) both CFD cases showed similar performance at positions $\mathrm{A} 2_{2}, \mathrm{~A} 3_{2}$ and $\mathrm{A} 4_{2}$ mostly in the lower part but not in the higher part of the profiles. At position $\mathrm{A}_{2}$ almost a perfect match between set 1 and set 2 cases were found between 0.033 and 0.55 of $z / z_{\text {ref }}$; conversely a large discrepancy was found between both CFD cases in the range 0.55 and 1 of $z / z_{\text {ref. }}$. Both CFD cases showed discrepancies with WT results below $z / z_{\text {ref }}=0.15$. Since the alignment of the approach-flow with the entrance of Canale Rosciano was decreasing with increasing $\alpha$ over the range of wind directions considered (see also Fig. 8c-d), the recirculation and separation zones along the Canale Rosciano were larger compared to the ones found for the wind direction $\alpha=240^{\circ}$.

For $\alpha=300^{\circ}$ (Fig. 9c) both CFD cases showed an evident overestimation, in terms of mean wind velocity, with respect to the WT case at positions $\mathrm{A} 22_{2}$ and mostly in the lower part of the profiles, between about 0.033 and 0.1 of $z / z_{\text {ref }}$. As showed also in Fig. 8e-f, the aforementioned overestimation was possible caused by the limitation of the RANS approach in predicting the separation and reversal of the flow occurred at the entrance of the Canale Rociano, where the position $\mathrm{A}_{2}$ is located. At position $\mathrm{A}_{2}$ a better agreement between the set 2 and WT cases, with respect to the set 1 case was found both in the lower and 

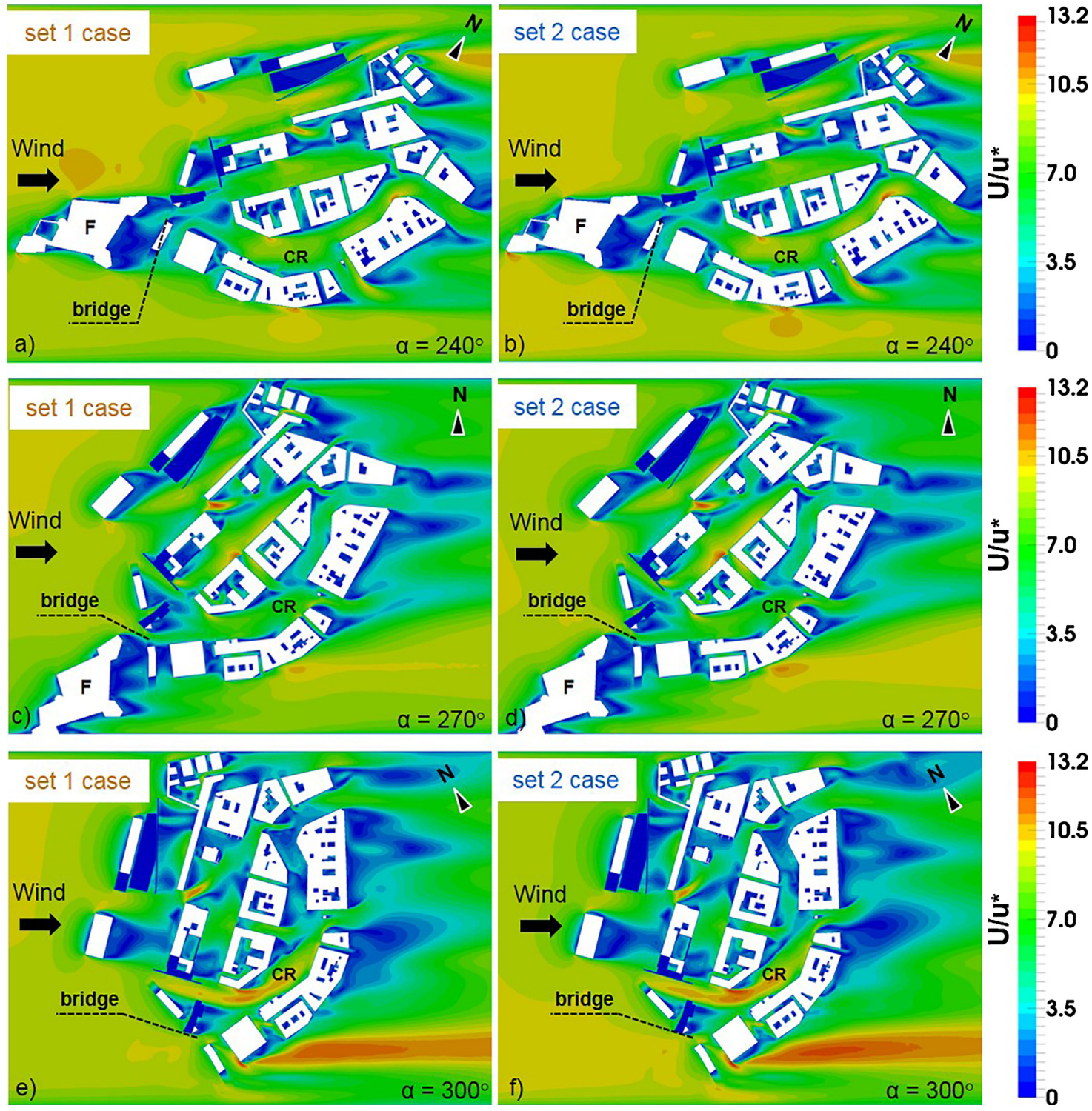

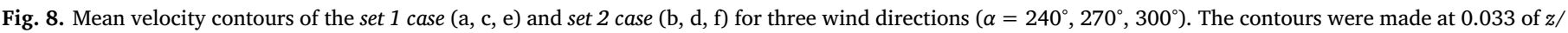

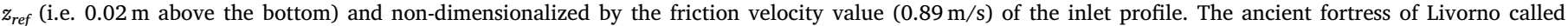
"Fortezza Antica", Canale Rosciano and the bridge on "Viale della Cinta Esterna" are indicated by "F", "CR" and "bridge" in the figures, respectively.

higher parts of the profile. At positions $A 4_{2}$ and $A 5_{2}$ the two CFD profiles were almost overlapped between 0.033 and 0.6 of $z / z_{\text {ref }}$ but not in satisfactory agreement mostly between about 0.033 and 0.3 of $z / z_{\text {ref }}$ with respect to the WT profiles.

\subsection{Vertical profiles of turbulent kinetic energy}

Turbulent kinetic energy $(k)$ profiles of WT tests, calculated using the velocity standard deviations $\sigma_{u}(z), \sigma_{\nu}(z)$ and $\sigma_{w}(z)$ measured at 15 different levels above the tunnel floor (i.e. from 0.02 to $0.60 \mathrm{~m}$ ), and CFD simulations were compared for the three wind directions at positions $\mathrm{A}_{2}-\mathrm{A} 5_{2}$ (Fig. 10). The measured turbulent kinetic energy profiles confirmed that canyoning effects likely occurred along Canale Rosciano, in agreement with the findings of Section 4.2. Indeed, whereas for all wind directions the mean velocities decrease especially in the lower part of the profiles from point $\mathrm{A} 2_{2}$ to $\mathrm{A} 5_{2}$ (Fig. 9) due to separation zones, the turbulent kinetic energy progressively increases (Fig. 10). Experimental and numerical turbulent kinetic energy profiles showed large discrepancies mostly in the lowest part of the profiles, which were generally underpredicted by numerical simulations. However, both set
1 and set 2 case predicted very similar in terms of profiles' shape and pick positions at the four positions $\mathrm{A} 2_{2}-\mathrm{A} 5_{2}$ with respect to WT values for $\alpha=240^{\circ}$ and $\alpha=270^{\circ}$. In contrast, the set 1 case shows wrong profiles' shape with respect to WT results for $\alpha=300^{\circ}$, except for the position $\mathrm{A} 5_{2}$, while the set 2 case performed similarly to the other directions.

\subsection{Yaw and pitch angles}

In order to better understand the wind-flow patterns inside Canale Rosciano, yaw $(\phi)$ and pitch $(\theta)$ angles at positions $\mathrm{A} 2_{1}-\mathrm{A} 5_{2}$, at 0.033 of $z / z_{\text {ref }}$, for WT tests and CFD simulations were compared for all the considered wind directions (Tables $1-3$ ). The yaw and pitch angles were calculated as follows, respectively:

$\phi(z)=a \tan \left(\frac{v}{u}\right)$

$\theta(z)=a \tan \left(\frac{w}{u}\right)$ 

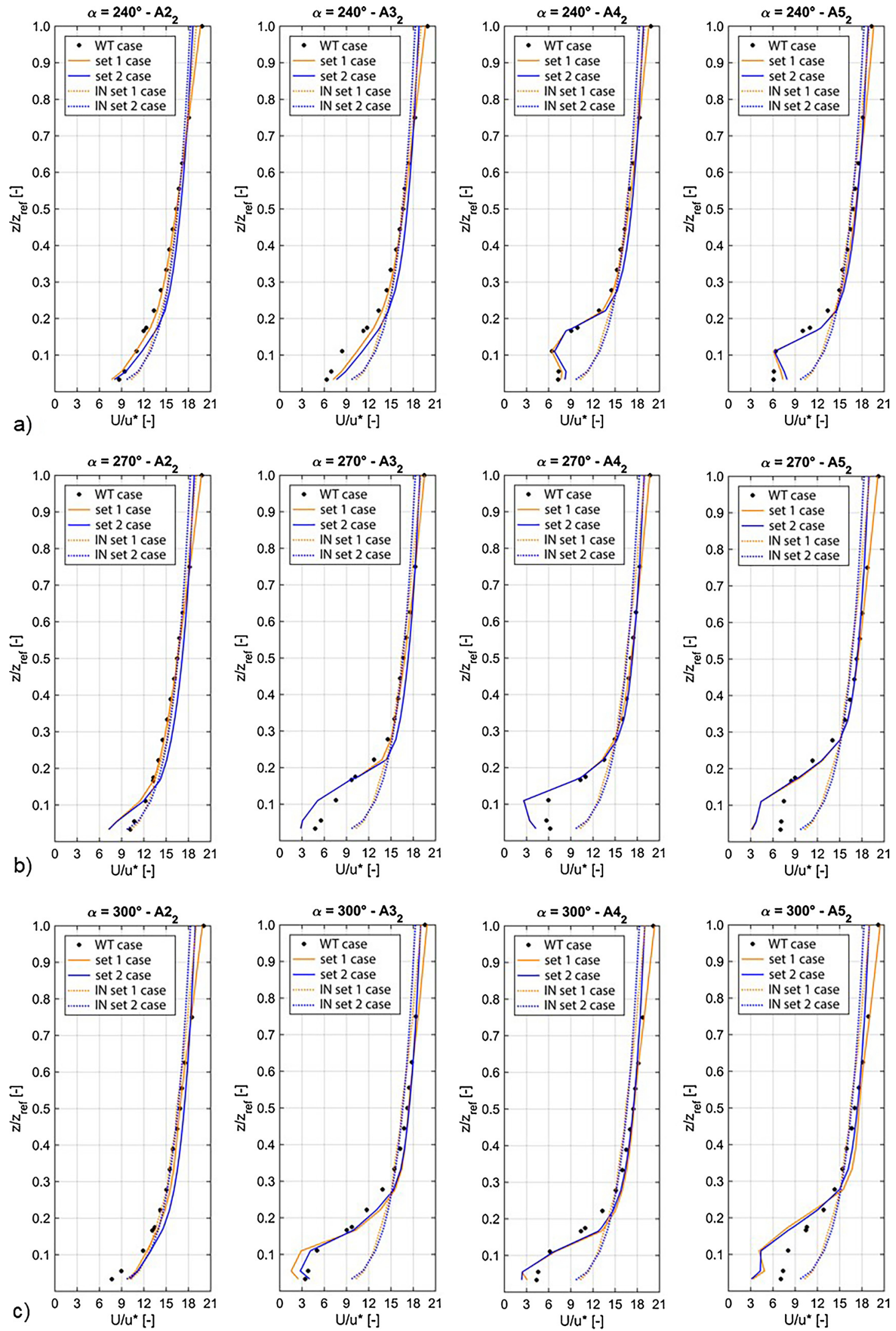

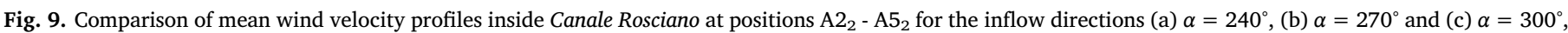

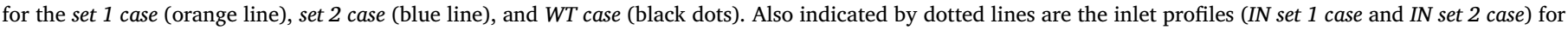
both CFD cases. (For interpretation of the references to colour in this figure legend, the reader is referred to the web version of this article.) 

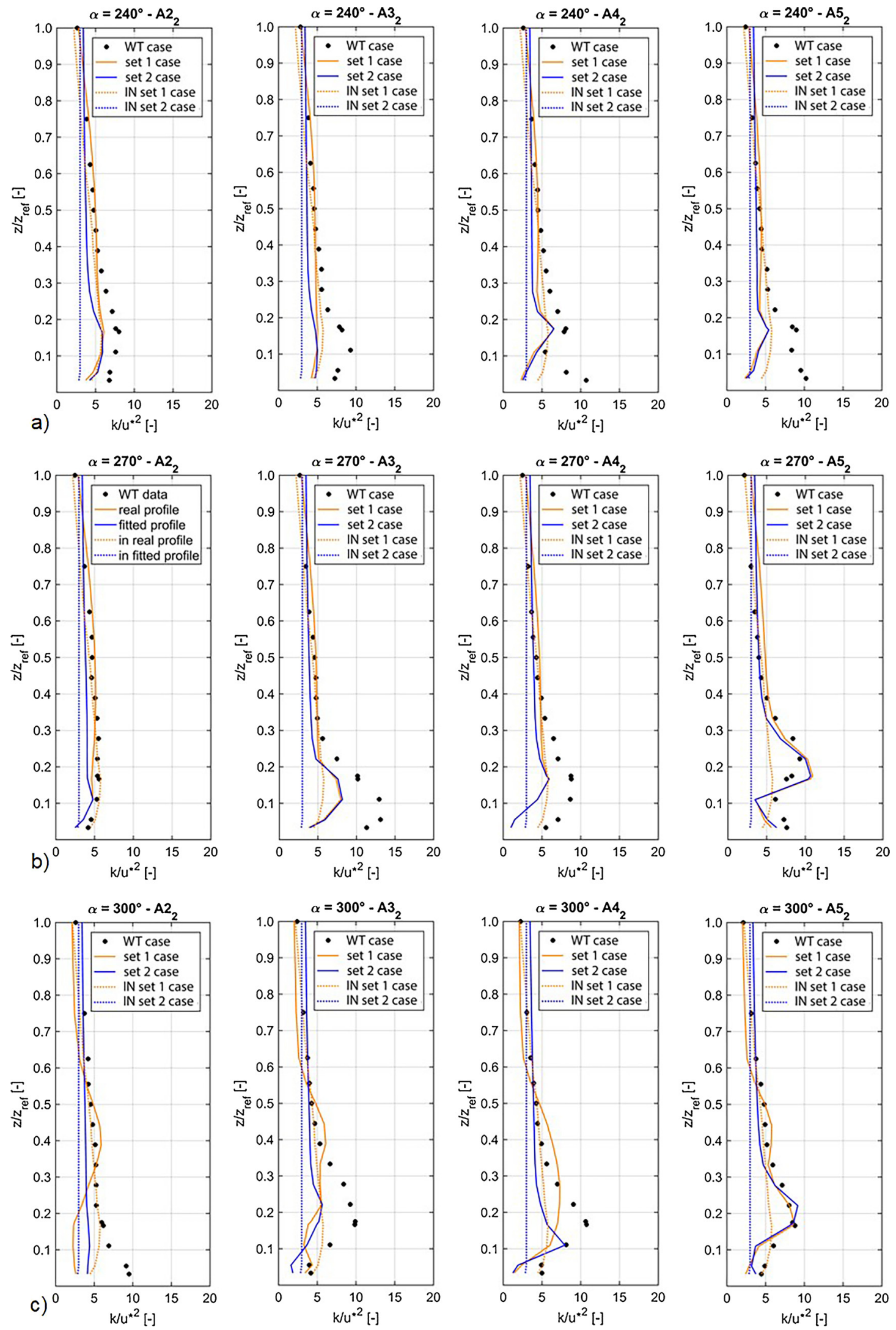

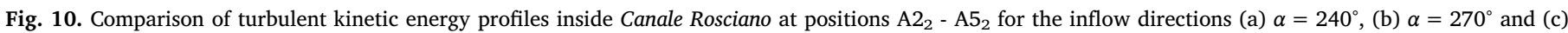

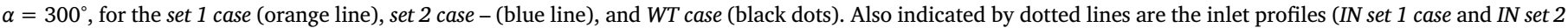
case) for both CFD cases. (For interpretation of the references to colour in this figure legend, the reader is referred to the web version of this article.) 
Table 1

Comparison of yaw $\phi(z)$ and pitch $\theta(z)$ angles for $W T$, set 1 and set 2 cases at positions $\mathrm{A} 2{ }_{1}-\mathrm{A} 5_{2}$ for the inflow direction $\alpha=240^{\circ}$ at $0.033 z / z_{\text {ref }}$ (i.e. at $0.02 \mathrm{~m}$ above the bottom). Positive values of $\phi(z)$ and $\theta(z)$ represent counterclockwise rotation around the $z$-axis and clockwise rotation around the $y$-axis, respectively.

\begin{tabular}{l|lll|lll}
\hline positions & WT case $\phi(z)$ & set 1 case $\phi(z)$ & set 2 case $\phi(z)$ & WT case $\theta(z)$ & set 1 case $\theta(z)$ & set 2 case $\theta(z)$ \\
\hline $\mathrm{A} 2_{1}$ & $-21.87^{\circ}$ & $-23.44^{\circ}$ & $-23.28^{\circ}$ & $15.0^{\circ}$ & $-1.24^{\circ}$ & $-1.56^{\circ}$ \\
$\mathrm{A} 2_{2}$ & $-17.59^{\circ}$ & $-18.51^{\circ}$ & $-18.77^{\circ}$ & $8.37^{\circ}$ & $-3.18^{\circ}$ & $-3.17^{\circ}$ \\
$\mathrm{A} 3_{1}$ & $24.79^{\circ}$ & $13.87^{\circ}$ & $13.10^{\circ}$ & $-3.88^{\circ}$ & $-1.53^{\circ}$ & $-1.70^{\circ}$ \\
$\mathrm{A} 3_{2}$ & $23.18^{\circ}$ & $14.61^{\circ}$ & $14.35^{\circ}$ & $-3.64^{\circ}$ & $-3.34^{\circ}$ & $-3.55^{\circ}$ \\
$\mathrm{A} 3_{3}$ & $-19.20^{\circ}$ & $-30.11^{\circ}$ & $-29.79^{\circ}$ & $13.56^{\circ}$ & $1.27^{\circ}$ & $1.45^{\circ}$ \\
$\mathrm{A} 4_{1}$ & $38.51^{\circ}$ & $34.40^{\circ}$ & $34.32^{\circ}$ & $-5.68^{\circ}$ & $-2.37^{\circ}$ & $-2.24^{\circ}$ \\
$\mathrm{A} 4_{2}$ & $38.49^{\circ}$ & $38.64^{\circ}$ & $38.52^{\circ}$ & $-8.38^{\circ}$ & $0.79^{\circ}$ & $0.71^{\circ}$ \\
$\mathrm{A} 5_{1}$ & $25.01^{\circ}$ & $23.26^{\circ}$ & $23.74^{\circ}$ & $-3.10^{\circ}$ & $-2.19^{\circ}$ & $-2.69^{\circ}$ \\
$\mathrm{A} 5_{2}$ & $0.24^{\circ}$ & $24.84^{\circ}$ & $26.01^{\circ}$ & $0.57^{\circ}$ & $2.06^{\circ}$ & $0.91^{\circ}$ \\
\hline
\end{tabular}

where $u, v$ and $w$ indicate the mean wind velocity values in the streamwise $(x)$, spanwise $(y)$ and vertical $(z)$ directions, respectively.

In general, while the differences of $\phi$ between the set 1 and set 2 cases were usually small, larger discrepancies between CFD (both cases) and WT results were observed for few specific locations and wind directions. This is shown in Fig. 11, where the horizontal velocity vectors $U$ of WT and CFD cases were superimposed on the mean wind speed contours of the set 2 case. Larger agreement in terms of $\phi$ between WT and CFD cases (for both CFD cases) was found where the highest mean wind speeds were observed:

- for $\alpha=240^{\circ}$ : positions $\mathrm{A} 2_{1}, \mathrm{~A} 2_{2}, \mathrm{~A} 4_{2}$ and $\mathrm{A} 5_{1}$ (Table 1 and Fig. 11a-b);

- for $\alpha=270^{\circ}$ : positions $\mathrm{A} 2_{2}$ and $\mathrm{A} 3_{3}$ (Table 2 and Fig. $11 \mathrm{c}-\mathrm{d}$ );

- for $\alpha=300^{\circ}$ : positions $\mathrm{A} 2_{2}$ (Table 3 and Fig. $11 \mathrm{e}-\mathrm{f}$ ).

In contrast, the measuring positions placed in the leeward zones (e.g. $\mathrm{A} 5_{2}$ for $\alpha=240^{\circ}, \mathrm{A} 3_{1}-\mathrm{A} 5_{2}$ for $\alpha=270^{\circ}$ and $\alpha=300^{\circ}$ ) of Canale Rosciano showed larger discrepancies between WT and CFD results in terms of $\phi$, confirming the limitations of the RANS approach in the accurate prediction of separation zones.

This limitation was further confirmed by comparing $\theta$ : while the set 1 and set 2 cases compared well with each other, the comparison with WT results showed much larger discrepancies with respect to $\phi$. It should be noted, however, that this parameter is particularly critical because slight uncertainties in the measuring position of the multihole probe or between the physical model (in the WT) and the geometrical model (in CFD) can determine large deviations between experiments and numerical results.

\section{Performance metrics}

In order to quantify the impact of the inflow conditions on urban wind flow prediction the statistical performance of both CFD cases was calculated using different validation metrics for the mean velocity magnitude, turbulent kinetic energy, and yaw and pitch angles (Chang \& Hanna, 2004; Gousseau, Blocken, \& van Heijst, 2013; Ricci, Kalkman et al., 2017; Schatzmann, Olesen, \& Franke, 2010).

For the mean velocity magnitude the fractional bias $(F B)$, normalized mean square error (NMSE), correlation coefficient $(R)$, and the fraction of data within a factor 1.3 (FAC1.3) were adopted. The same aforementioned metrics, but using the FAC2.0 instead of FAC1.3, were also adopted for the turbulent kinetic energy. For the yaw and pitch angles the $R$ and FAC2.0 metrics were used. The ideal values corresponding to complete agreement between CFD and WT results are $F B=0, N M S E=0, R=1$ and $F A C(1.3 \& 2.0)=1$. The validation metrics were calculated as follow:

$F B=2 \frac{(\bar{O}-\bar{P})}{(\bar{O}+\bar{P})}$

$N M S E=\frac{(\overline{O-P})^{2}}{(\bar{O} \cdot \bar{P})}$

$R=2 \frac{\overline{(O-\bar{O})} \cdot \overline{(P-\bar{P})}}{\left(\sigma_{O} \cdot \sigma_{P}\right)}$

FAC1.3 $=\frac{1}{N} \sum_{i=1}^{N} n_{i} \quad n_{i}=\left\{\begin{array}{c}1 \text { for } 0.77 \leq \frac{P_{i}}{O_{i}} \leq 1.3 \\ 0 \text { else }\end{array}\right.$

FAC2.0 $=\frac{1}{N} \sum_{i=1}^{N} n_{i} \quad n_{i}=\left\{\begin{array}{c}1 \text { for } 0.50 \leq \frac{P_{i}}{O_{i}} \leq 2.0 \\ 0 \text { else }\end{array}\right.$

where $P$ and $O$ are the predicted (CFD) and the observed (WT) values, and $\sigma_{P}$ and $\sigma_{O}$ are the standard deviations over a specific dataset.

The validation metrics were calculated on horizontal planes at 0.033 of $z / z_{\text {ref }}$, for all measuring positions A and L (overall 25 positions). However, due to presence of buildings and bridges at the considered level (i.e. at 0.033 of $z / z_{\text {ref }}$ ), the number of measurements (i.e. samples) was marginally reduced with respect to the aforementioned overall value (i.e. 25). The samples considered were finally 18, 20 and 17 for $\alpha=240^{\circ}, \alpha=270^{\circ}$ and $\alpha=300^{\circ}$, respectively.

\subsection{Statistical performance: wind speed at $0.033 \mathrm{z} / \mathrm{z}_{\text {ref }}$}

The results for $0.033 z / z_{\text {ref }}$ are given in Table 4 and graphically displayed in Fig. 12. In general, the statistical performance for the mean wind speed ratio $U / u^{*}$ confirmed the considerations previously made in Section 4.2:

- a very good agreement between both CFD cases and the WT case for $\alpha=240^{\circ}$;

- a slightly lower performance of both CFD cases with respect to the WT case for $\alpha=270^{\circ}$ and $\alpha=300^{\circ}$.

Table 2

Comparison of yaw $\phi(z)$ and pitch $\theta(z)$ angles for $W T$, set 1 and set 2 cases at positions $\mathrm{A} 2_{1}-\mathrm{A} 5_{2}$ for the inflow direction $\alpha=270^{\circ}$ at 0.033 of $z / z_{\text {ref }}$ (i.e. at $0.02 \mathrm{~m}$ above the bottom). Positive values of $\phi(z)$ and $\theta(z)$ represent counterclockwise rotation around the $z$-axis and clockwise rotation around the $y$-axis, respectively.

\begin{tabular}{l|lll|lll}
\hline positions & WT case $\phi(z)$ & set 1 case $\phi(z)$ & set 2 case $\phi(z)$ & WT case $\theta(z)$ & set 1 case $\theta(z)$ & set 2 case $\theta(z)$ \\
\hline $\mathrm{A} 2_{1}$ & $11.88^{\circ}$ & $2.85^{\circ}$ & $2.82^{\circ}$ & $0.08^{\circ}$ & $-2.18^{\circ}$ & $-2.16^{\circ}$ \\
$\mathrm{A} 2_{2}$ & $2.80^{\circ}$ & $5.69^{\circ}$ & $5.98^{\circ}$ & $-1.55^{\circ}$ & $2.50^{\circ}$ & $2.61^{\circ}$ \\
$\mathrm{A} 3_{1}$ & $24.81^{\circ}$ & $64.61^{\circ}$ & $64.60^{\circ}$ & $-5.47^{\circ}$ & $5.46^{\circ}$ & $6.99^{\circ}$ \\
$\mathrm{A} 3_{2}$ & $26.06^{\circ}$ & $63.60^{\circ}$ & $63.87^{\circ}$ & $9.04^{\circ}$ & $-28.13^{\circ}$ & $-28.34^{\circ}$ \\
$\mathrm{A} 3_{3}$ & $18.89^{\circ}$ & $25.47^{\circ}$ & $25.79^{\circ}$ & $-5.24^{\circ}$ & $2.12^{\circ}$ & $1.94^{\circ}$ \\
$\mathrm{A} 4_{1}$ & $18.67^{\circ}$ & $78.37^{\circ}$ & $78.14^{\circ}$ & $-5.25^{\circ}$ & $40.48^{\circ}$ & $31.99^{\circ}$ \\
$\mathrm{A} 4_{2}$ & $17.02^{\circ}$ & $87.19^{\circ}$ & $86.46^{\circ}$ & $-4.93^{\circ}$ & $39.69^{\circ}$ & $33.65^{\circ}$ \\
$\mathrm{A} 5_{1}$ & $12.27^{\circ}$ & $71.49^{\circ}$ & $71.31^{\circ}$ & $0.22^{\circ}$ & $15.58^{\circ}$ & $15.87^{\circ}$ \\
$\mathrm{A} 5_{2}$ & $5.29^{\circ}$ & $34.49^{\circ}$ & $27.41^{\circ}$ & $-0.79^{\circ}$ & $23.32^{\circ}$ & $20.66^{\circ}$ \\
\hline
\end{tabular}


Table 3

Comparison of yaw $\phi(\mathrm{z})$ and pitch $\theta(\mathrm{z})$ angles for $W T$, set 1 and set 2 cases at positions $\mathrm{A} 2{ }_{1}-\mathrm{A} 5_{2}$ for the inflow direction $\alpha=300^{\circ}$ at 0.033 of $z / z_{\text {ref }}$ (i.e. at $0.02 \mathrm{~m}$ above the bottom). Positive values of $\phi(z)$ and $\theta(z)$ represent counterclockwise rotation around the $z$-axis and clockwise rotation around the $y$-axis, respectively.

\begin{tabular}{l|lll|lll}
\hline positions & WT case $\phi(z)$ & set 1 case $\phi(z)$ & set 2 case $\phi(z)$ & WT case $\theta(z)$ & set 1 case $\theta(z)$ & set 2 case $\theta(z)$ \\
\hline $\mathrm{A} 2_{1}$ & $30.49^{\circ}$ & $38.07^{\circ}$ & $40.47^{\circ}$ & $-11.02^{\circ}$ & $-4.01^{\circ}$ & $-5.06^{\circ}$ \\
$\mathrm{A} 2_{2}$ & $28.77^{\circ}$ & $23.45^{\circ}$ & $24.07^{\circ}$ & $-5.38^{\circ}$ & $-2.53^{\circ}$ & $-1.66^{\circ}$ \\
$\mathrm{A} 3_{1}$ & $16.63^{\circ}$ & $83.07^{\circ}$ & $85.36^{\circ}$ & $-1.78^{\circ}$ & $-56.73^{\circ}$ & $-62.94^{\circ}$ \\
$\mathrm{A} 3_{2}$ & $5.27^{\circ}$ & $85.05^{\circ}$ & $85.35^{\circ}$ & $-1.82^{\circ}$ & $59.67^{\circ}$ & $70.11^{\circ}$ \\
$\mathrm{A} 3_{3}$ & $23.81^{\circ}$ & $30.79^{\circ}$ & $40.58^{\circ}$ & $1.21^{\circ}$ & $5.09^{\circ}$ & $1.38^{\circ}$ \\
$\mathrm{A} 4_{1}$ & $-3.93^{\circ}$ & $-14.04^{\circ}$ & $-12.65^{\circ}$ & $-5.47^{\circ}$ & $27.49^{\circ}$ & $19.14^{\circ}$ \\
$\mathrm{A} 4_{2}$ & $-3.50^{\circ}$ & $0.63^{\circ}$ & $10.54^{\circ}$ & $-5.18^{\circ}$ & $-12.65^{\circ}$ & $-31.74^{\circ}$ \\
$\mathrm{A} 5_{1}$ & $1.93^{\circ}$ & $10.51^{\circ}$ & $48.24^{\circ}$ & $5.86^{\circ}$ & $-6.86^{\circ}$ & $-28.80^{\circ}$ \\
$\mathrm{A} 5_{2}$ & $0.20^{\circ}$ & $13.16^{\circ}$ & $9.02^{\circ}$ & $1.42^{\circ}$ & $20.57^{\circ}$ & $9.67^{\circ}$ \\
\hline
\end{tabular}
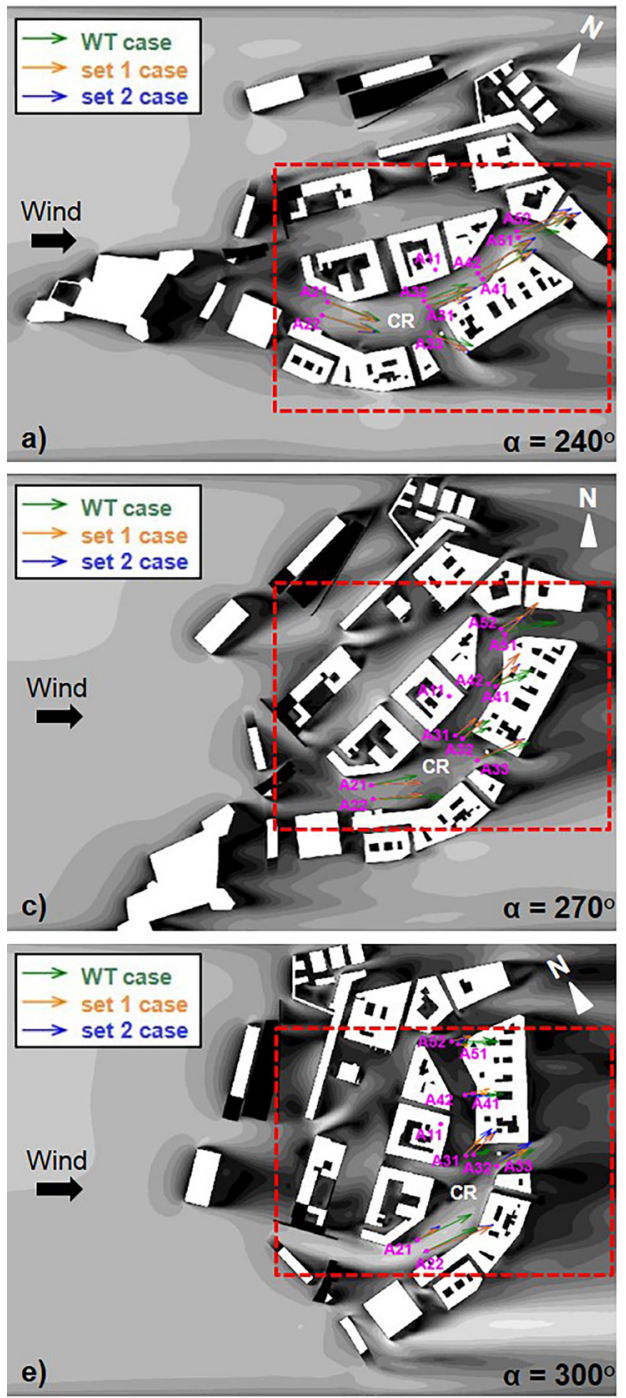
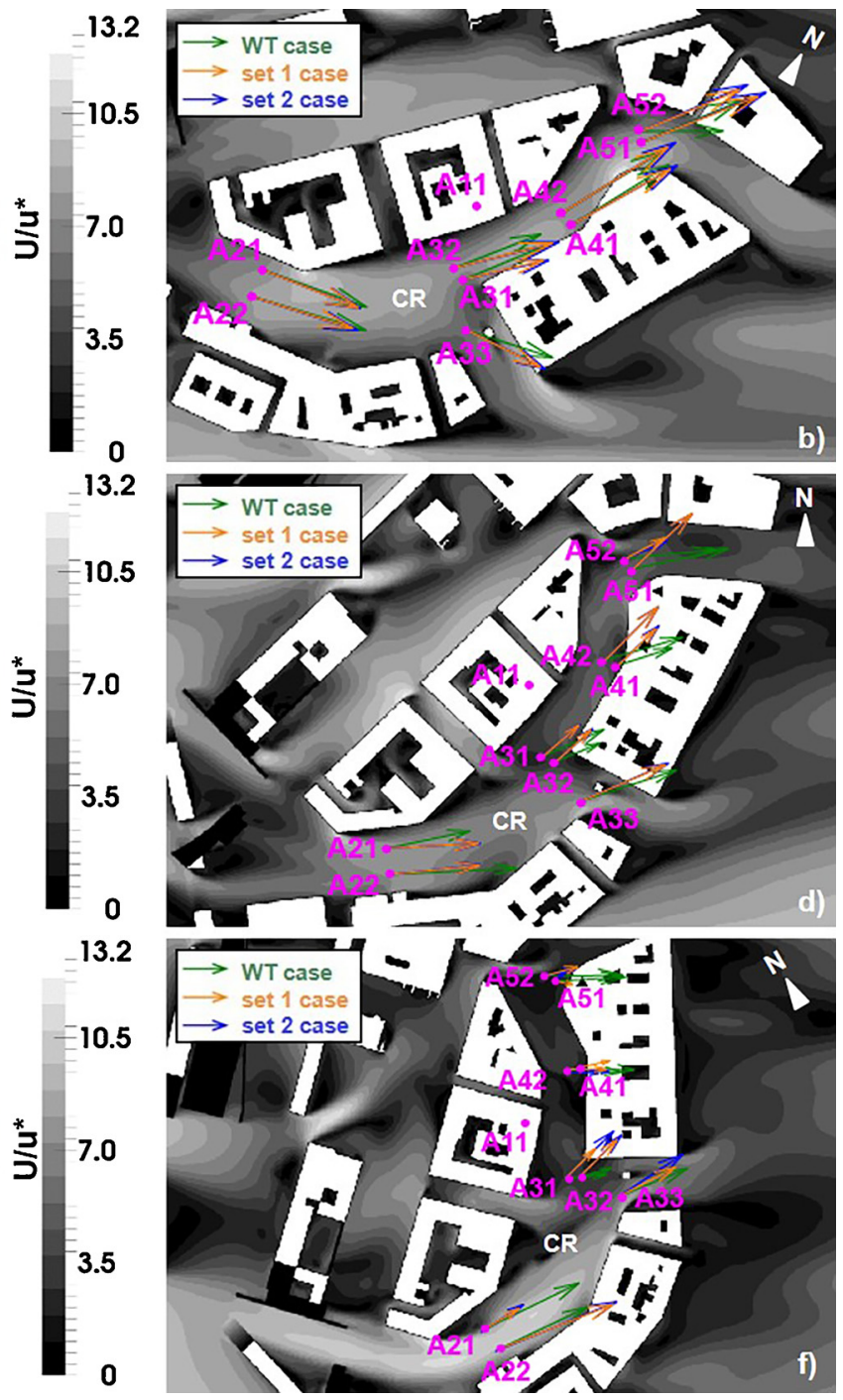

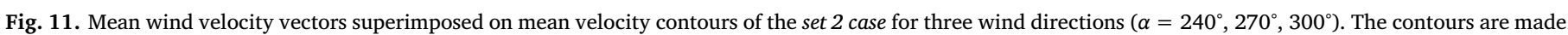

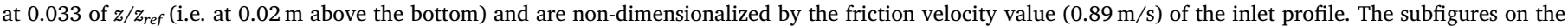
right side (b, d, f) are enlarged views of the dashed red rectangle in subfigures (a,c) and (e), respectively. Canale Rosciano is indicated by "CR" in the figures.

For the incoming wind direction $\alpha=240^{\circ}$ the $F B$ values of the set 1 and set 2 cases showed nearly the same distribution around the diagonal, indicating a similar agreement with WT results. A better correlation $(R)$ with WT results was observed for the set 1 case $(77 \%)$ than for the set 2 case (71\%). A gap of $6 \%$ was also found in terms of FAC1.3, with a value of $89 \%$ for the set 1 case and $83 \%$ for the set 2 case.

For $\alpha=270^{\circ} \mathrm{FB}$, NMSE and FAC1.3 showed almost the same performance of the set 1 and set 2 cases, while the correlation coefficient $(R)$ indicated a slightly better agreement of the set 1 case with the WT case compared to the set 2 case.
For $\alpha=300^{\circ}$ a slightly better correlation (R) with $W T$ results was found for the set 1 case (59\%) than for the set 2 case (52\%). A gap of $6 \%$ was observed in terms of FAC1.3, with a value of $56 \%$ for the set 1 case and $50 \%$ for the set 2 case.

\subsection{Statistical performance: turbulent kinetic energy at $0.033 \mathrm{z} / z_{\text {ref }}$}

The same procedure described in Section 5.1 was applied to turbulent kinetic energy. The results for $0.033 z / z_{\text {ref }}$ are shown in Table 5 and displayed in Fig. 13. However, in order to better appreciate the 
Table 4

Validation metrics for mean wind velocity $U(F B=$ Fractional Bias, NMSE = Normalized Mean Square Error, $R=$ correlation coefficient, FAC1.3 = Fraction of data within a factor of 1.3) for set 1 and set 2 cases, three inflow directions $\left(\alpha=240^{\circ}, \alpha=270^{\circ}, \alpha=300^{\circ}\right)$, and 25 measurement positions (A and L) at 0.033 of $z / z_{\text {ref }}$ (i.e. at $0.02 \mathrm{~m}$ above the bottom). Also indicated (in second and third columns) are the number of samples (measurement positions) that are not occupied by the urban model and are therefore available for statistical analysis (note that this depends on the wind direction as positions $\mathrm{L}$ are fixed with respect to the WT section).

\begin{tabular}{|c|c|c|c|}
\hline$\alpha=240^{\circ}, z / z_{r e f}=0.033$ & set 1 case $v s$ WT case & set 2 case $v s$ WT case & ideal value \\
\hline$F B$ & -0.04 & -0.07 & 0 \\
\hline NMSE & 0.04 & 0.05 & 0 \\
\hline$R$ & 0.77 & 0.71 & 1 \\
\hline FAC1.3 & 0.89 & 0.83 & 1 \\
\hline samples & 18 & 18 & 25 \\
\hline$\alpha=270^{\circ}, z / z_{r e f}=0.033$ & set 1 case $v s$ WT case & set 2 case $v s$ WT case & ideal value \\
\hline$F B$ & 0.11 & 0.10 & 0 \\
\hline NMSE & 0.11 & 0.11 & 0 \\
\hline$R$ & 0.66 & 0.63 & 1 \\
\hline FAC1.3 & 0.56 & 0.56 & 1 \\
\hline samples & 20 & 20 & 25 \\
\hline$\alpha=300^{\circ}, z / z_{r e f}=0.033$ & set 1 case $v s$ WT case & set 2 case $v s$ WT case & ideal value \\
\hline$F B$ & 0.12 & 0.11 & 0 \\
\hline NMSE & 0.18 & 0.20 & 0 \\
\hline$R$ & 0.59 & 0.52 & 1 \\
\hline FAC1.3 & 0.56 & 0.50 & 1 \\
\hline samples & 17 & 17 & 25 \\
\hline
\end{tabular}

performance difference between both CFD cases with respect to WT case, a fraction of data positions FAC2.0 instead of FAC1.3 was used.

In general, the statistical performance for the turbulent kinetic energy ratio $k / u^{* 2}$ confirmed the trend of both CFD cases with respect to the WT case previously highlighted in Fig. 10:

- The results of both CFD cases showed a remarkable underestimation for the three reference wind directions compared to the WT case;

- CFD case 1 and 2 displayed a similar performance for the reference wind directions $\alpha=240^{\circ}$ and $\alpha=270^{\circ}$, but not for $\alpha=300^{\circ}$.

For $\alpha=240^{\circ}$, the $F B$ and NMSE values of the set 1 (0.75 and 0.92) and set 2 (0.72 and 0.83$)$ cases displayed nearly a similar underestimation with respect to WT data. The correlation (R) with WT results was almost zero for both CFD cases; however this is just because of some outliers for $k_{W T} / u^{* 2}$ greater than about 10 which correspond to the most sheltered positions, i.e. $\mathrm{A} 4_{1,2}$ and $\mathrm{A} 5_{1,2}$. Conversely, the matric FAC2.0 showed that $55 \%$ of numerical data, for both CFD cases, were within a deviation of $50 \%$.

For $\alpha=270^{\circ}$, the $F B$ values of the set $1(0.81)$ and set $2(0.78)$ cases showed almost the same performance already observed for $\alpha=240^{\circ}$. In contrast, the NMSE values of set 1 (1.20) and set 2 (1.14) cases indicated a higher dispersion of simulated data around the diagonal compared to the previous wind direction. In that respect, the FAC2.0 showed that a reduced number of samples were within a deviation of $50 \%$ for both CFD cases with respect to the case of $\alpha=240^{\circ}$. Again a very similar low correlation $(R)$ with WT data was found between set $1(0.26)$ and set 2 $(0.25)$ cases.

For $\alpha=300^{\circ}$, all the metrics showed bigger differences between set 1 and set 2 cases, compared to the previous wind directions. The $F B$ showed a better alignment of set 2 data (0.59) with respect to the ones of set 1 (0.66). A better performance of set 2 compared set 1 was also confirmed by the NMSE metric, which displayed a tighter dispersion of set 2 data (0.62) compared to set 1 data $(0.80)$. The same trend was remarked again by the correlation $(R)$, for which a gap of $17 \%$ was found between set $1(0.38)$ and set $2(0.55)$ cases. In contrast, the FAC2.0 displayed that $53 \%$ and $47 \%$ of simulated data, belonging to set 1 and set 2 respectively, were within a deviation of $50 \%$ compared to WT data.

\subsection{Statistical performance: yaw and pitch angles at $0.033 \mathrm{z} / \mathrm{z}_{\text {ref }}$}

The same procedure described in Sections 5.1 and 5.2 was applied to yaw and pitch angles. However, only two metrics were used in the
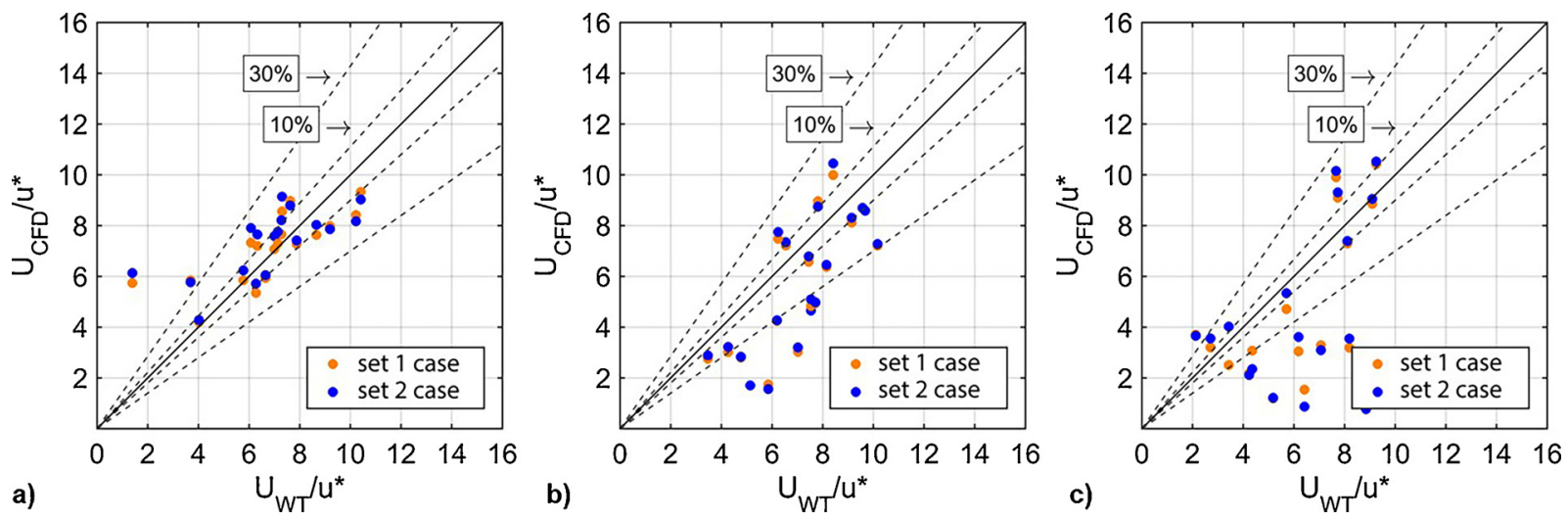

Fig. 12. Comparison of CFD (set 1 and set 2 cases) and WT data at the monitored positions A and L for three inflow directions: (a) $\alpha=240^{\circ}$, (b) $\alpha=270^{\circ}$, (c) $\alpha=300^{\circ}$ at 0.033 of $z / z_{\text {ref }}$ (i.e. at $0.02 \mathrm{~m}$ above the bottom). Dashed black lines correspond to $10 \%$ and $30 \%$ errors, as indicated. 
Table 5

Validation metrics for turbulent kinetic energy $k$ (FB $=$ Fractional Bias, NMSE $=$ Normalized Mean Square Error, $R=$ correlation coefficient, FAC1.3 = Fraction of data within a factor of 1.3) for set 1 and set 2 cases, three inflow directions $\left(\alpha=240^{\circ}, \alpha=270^{\circ}, \alpha=300^{\circ}\right)$, and 25 measurement positions (A and L) at 0.033 of $z / z_{\text {ref }}$ (i.e. at $0.02 \mathrm{~m}$ above the bottom). Also indicated (in second and third columns) are the number of samples (measurement positions) that are not occupied by the urban model and are therefore available for statistical analysis (note that this depends on the wind direction as positions $\mathrm{L}$ are fixed with respect to the WT section).

\begin{tabular}{|c|c|c|c|}
\hline$\alpha=240^{\circ}, z / z_{r e f}=0.033$ & set 1 case $v s$ WT case & set 2 case $v s$ WT case & ideal value \\
\hline$F B$ & 0.75 & 0.72 & 0 \\
\hline NMSE & 0.92 & 0.83 & 0 \\
\hline$R$ & 0.03 & 0.04 & 1 \\
\hline FAC2.0 & 0.55 & 0.55 & 1 \\
\hline Samples & 18 & 18 & 25 \\
\hline$\alpha=270^{\circ}, z / z_{\text {ref }}=0.033$ & set 1 case $v s$ WT case & set 2 case $v s$ WT case & ideal value \\
\hline$F B$ & 0.81 & 0.78 & 0 \\
\hline NMSE & 1.20 & 1.14 & 0 \\
\hline$R$ & 0.26 & 0.25 & 1 \\
\hline FAC2.0 & 0.50 & 0.50 & 1 \\
\hline Samples & 20 & 20 & 25 \\
\hline$\alpha=300^{\circ}, z / z_{\text {ref }}=0.033$ & set 1 case $v s$ WT case & set 2 case $v s$ WT case & ideal value \\
\hline$F B$ & 0.66 & 0.59 & 0 \\
\hline NMSE & 0.80 & 0.62 & 0 \\
\hline$R$ & 0.38 & 0.55 & 1 \\
\hline FAC2.0 & 0.53 & 0.47 & 1 \\
\hline samples & 17 & 17 & 25 \\
\hline
\end{tabular}
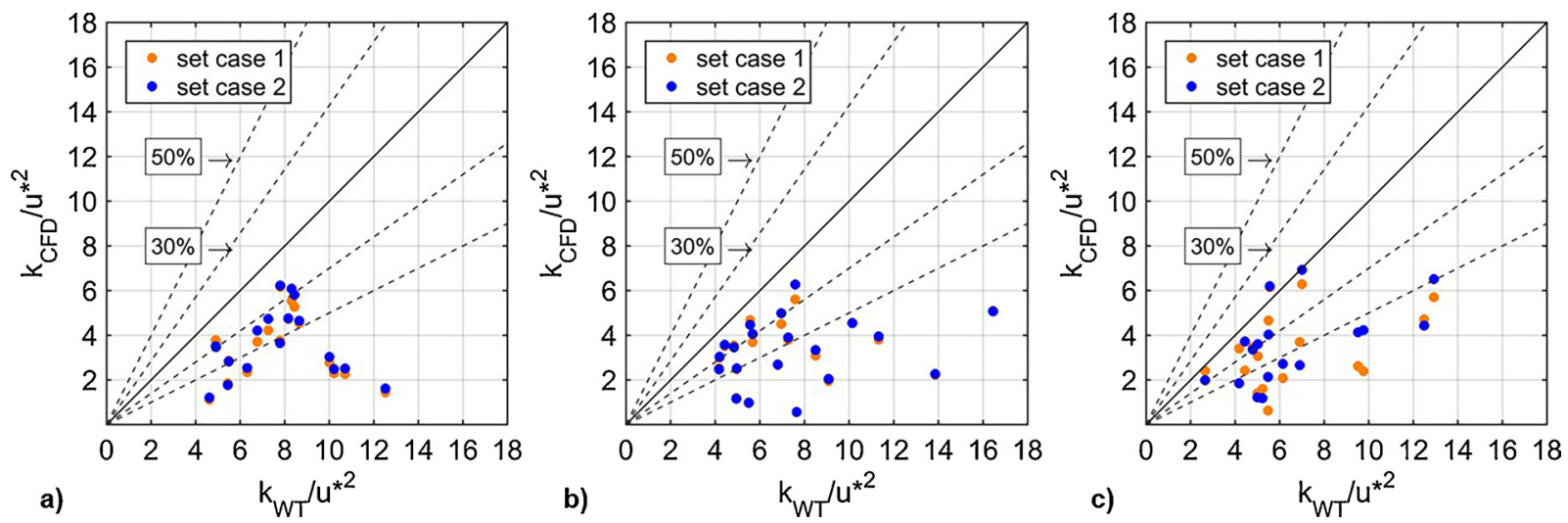

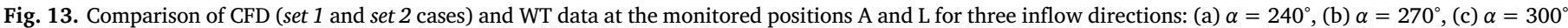
at 0.033 of $z / z_{\text {ref }}$ (i.e. at $0.02 \mathrm{~m}$ above the bottom). Dashed black lines correspond to $30 \%$ and $50 \%$ errors, as indicated.

Table 6

Validation metrics for yaw angle $\phi(z)(R=$ correlation coefficient and FAC2.0 = Fraction of data within a factor of 2.0$)$ for set 1 and set 2 cases, three inflow directions ( $\alpha=240^{\circ}, \alpha=270^{\circ}, \alpha=300^{\circ}$ ), and 25 measurement positions (A and L) at 0.033 of $z / z_{\text {ref }}$ (i.e. at $0.02 \mathrm{~m}$ above the bottom). Also indicated (in second and third columns) are the number of samples (measurement positions) that are not occupied by the urban model and are therefore available for statistical analysis (note that this depends on the wind direction as positions L are fixed with respect to the WT section).

\begin{tabular}{|c|c|c|c|}
\hline$\alpha=240^{\circ}, z / z_{\text {ref }}=0.033$ & set 1 case $v s$ WT case & set 2 case $v s$ WT case & ideal value \\
\hline$R$ & 0.85 & 0.84 & 1 \\
\hline FAC2.0 & 0.89 & 0.83 & 1 \\
\hline Samples & 18 & 18 & 25 \\
\hline$\alpha=270^{\circ}, z / z_{\text {ref }}=0.033$ & set 1 case $v s$ WT case & set 2 case $v s$ WT case & ideal value \\
\hline$R$ & 0.58 & 0.59 & 1 \\
\hline FAC2.0 & 0.45 & 0.45 & 1 \\
\hline Samples & 20 & 20 & 25 \\
\hline$\alpha=300^{\circ}, z / z_{\text {ref }}=0.033$ & set 1 case $v s$ WT case & set 2 case $v s$ WT case & ideal value \\
\hline$R$ & 0.31 & 0.30 & 1 \\
\hline FAC2.0 & 0.29 & 0.35 & 1 \\
\hline samples & 17 & 17 & 25 \\
\hline
\end{tabular}


Table 7

Validation metrics for pitch angle $\theta(z)(R=$ correlation coefficient and FAC2.0 = Fraction of data within a factor of 2.0$)$ for set 1 and set 2 cases, three inflow directions $\left(\alpha=240^{\circ}, \alpha=270^{\circ}, \alpha=300^{\circ}\right.$ ), and 25 measurement positions (A and L) at 0.033 of $z / z_{\text {ref }}$ (i.e. at $0.02 \mathrm{~m}$ above the bottom). Also indicated (in second and third columns) are the number of samples (measurement positions) that are not occupied by the urban model and are therefore available for statistical analysis (note that this depends on the wind direction as positions L are fixed with respect to the WT section).

\begin{tabular}{|c|c|c|c|}
\hline$\alpha=240^{\circ}, z / z_{r e f}=0.033$ & set 1 case $v s$ WT case & set 2 case $v s$ WT case & ideal value \\
\hline$R$ & -0.26 & 0.15 & 1 \\
\hline FAC2.0 & 0.39 & 0.17 & 1 \\
\hline samples & 18 & 18 & 25 \\
\hline$\alpha=270^{\circ}, z / z_{\text {ref }}=0.033$ & set 1 case $v s$ WT case & set 2 case $v s$ WT case & ideal value \\
\hline$R$ & -0.12 & -0.01 & 1 \\
\hline FAC2.0 & 0.30 & 0.25 & 1 \\
\hline samples & 20 & 20 & 25 \\
\hline$\alpha=300^{\circ}, z / z_{r e f}=0.033$ & set 1 case $v s$ WT case & set 2 case $v s$ WT case & ideal value \\
\hline$R$ & 0.33 & -0.26 & 1 \\
\hline \multirow[t]{2}{*}{ FAC2.0 } & 0.29 & 0.18 & 1 \\
\hline & 17 & 17 & 25 \\
\hline
\end{tabular}

present section: correlation coefficient $R$ and a fraction of data positions FAC2.0. FB and NMSE could not be used since the yaw and pitch angles can assume both positive and negative values (Gousseau et al., 2013). The results for the three wind directions at a height of $0.033 \mathrm{z} / z_{\text {ref }}$ are given in Tables 6 and 7 and displayed in Figs. 14 and 15. As indicated in Section 4.4 the discrepancies between CFD and WT results in terms of yaw and pitch angles were generally quite large.

\subsubsection{Yaw angle}

For $\alpha=240^{\circ}$ the correlation coefficient $R$ of the set 1 and set 2 cases showed quite a high value with WT results. A gap of $6 \%$ was found in terms of FAC2.0, with a value of $89 \%$ for the set 1 case and $83 \%$ for the set 2 case. A similar trend was found for the wind direction $\alpha=270^{\circ}$, where both of metrics showed similar performance for both CFD cases. For $\alpha=300^{\circ}$ a slightly tighter distribution around the diagonal was found for the set 1 case than for the set 2 case. A gap of $6 \%$ was found in terms of $F A C 2.0$, with a value of $35 \%$ for the set 2 case and $29 \%$ for the set 1 case (Table 6 and Fig. 14).

\subsubsection{Pitch angle}

In agreement with results already discussed in Section 4.4, Table 7 and Fig. 15 confirmed an unsatisfactory agreement between CFD and WT results for all incoming wind directions considered. However, the set 1 case showed a slightly better agreement compared to the set 2 one in terms of FAC2.0, with gaps of $22 \%, 5 \%$ and $11 \%$ respectively found for the wind directions $240^{\circ}, 270^{\circ}$ and $300^{\circ}$, between set 1 and set 2 cases.

\section{Discussion and conclusions}

In the present study, the impact of two sets of inflow conditions, termed set 1 and set 2 , on wind flow modeling in an urban environment was investigated. A district of Livorno city (Italy), the so-called Quartiere La Venezia, was selected as a case study and 3D steady-state RANS simulations were performed on a reduced-scale urban model (1:300) of this district, for three wind directions $\left(\alpha=240^{\circ}, 270^{\circ}\right.$ and $\left.300^{\circ}\right)$. The results in terms of mean wind velocity $(U)$, turbulent kinetic energy $(k)$, yaw $(\phi)$ and pitch $(\theta)$ angles were compared with WT results obtained by testing the same reduced-scale urban model at the Department of Civil, Chemical and Environmental Engineering (DICCA) of the University of Genoa. Several limitations to this study should be noted:

- The study was carried out on a single urban district and only three reference wind directions were considered both for WT tests and CFD simulations.

- The geometry used for the CFD simulations was not perfectly coincident with the physical model employed in the WT tests.

- The number of measuring positions taken into account for the WT tests and CFD simulations was limited to 25.

- Due to the limitations of the WT equipment (i.e. the traverse system), mean wind velocities and velocity standard deviations were measured from 0.033 to $0.44 z / z_{\text {ref }}$ (above the tunnel floor - by means of 15 measuring positions) and from 0.9 and $1.0 z / z_{\text {ref }}$ (near the top wall - by means of 8 measuring positions).

- Due to the size of the computational domain the 3D steady-state
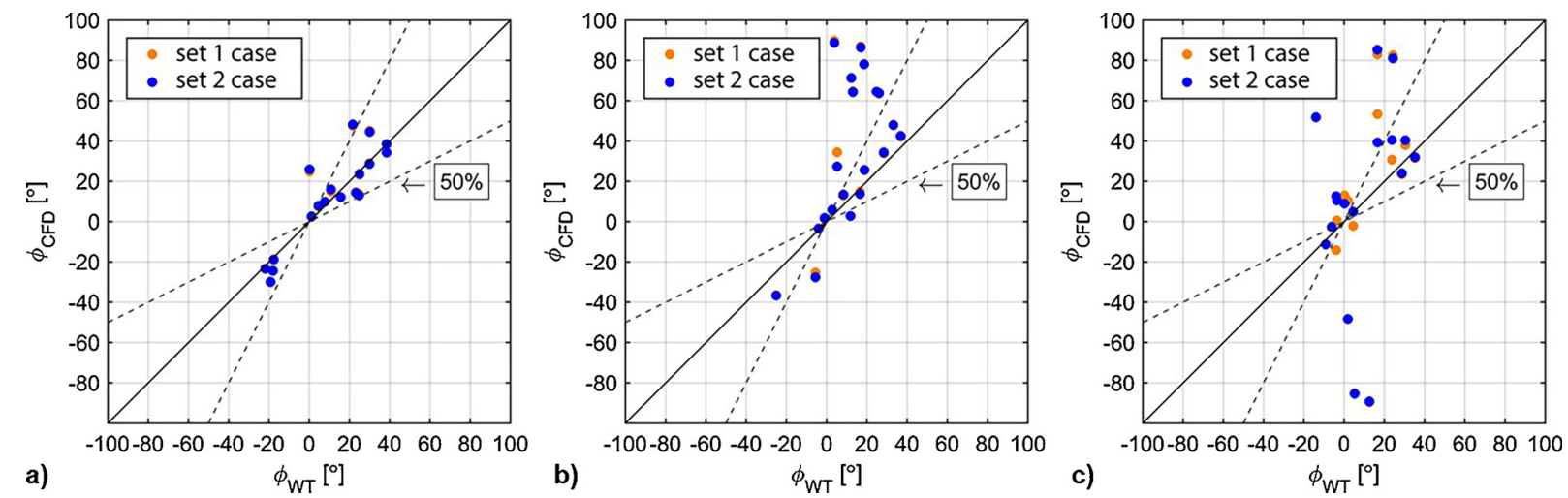

Fig. 14. Comparison of CFD (set 1 and set 2 cases) and WT data of yaw angle $\phi(z)$ at positions A and L for three inflow directions: (left) $\alpha=240^{\circ}$, (center) $\alpha=270^{\circ}$, (right) $\alpha=300^{\circ}$, at 0.033 of $z / z_{\text {ref }}$ (i.e. at $0.02 \mathrm{~m}$ above the bottom). Dashed black lines correspond to a $50 \%$ error, as indicated. 

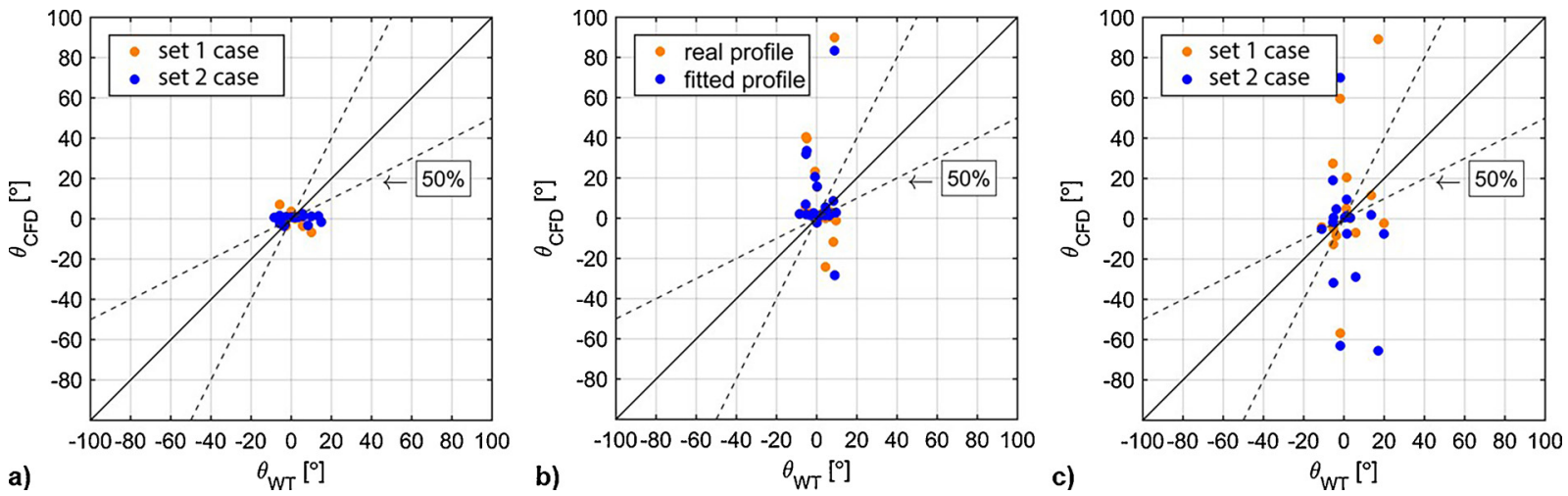

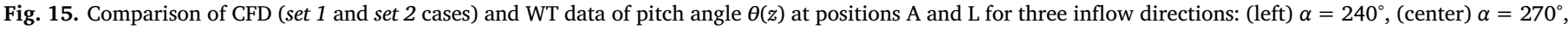
(right) $\alpha=300^{\circ}$, at 0.033 of $z / z_{\text {ref }}$ (i.e. at $0.02 \mathrm{~m}$ above the bottom). Dashed black lines correspond to a $50 \%$ error, as indicated.

RANS approach was used, which is known to be somehow inaccurate especially in separation zones. This means that such simulations are not expected to perfectly match experimental data because of the numerical approach adopted. In that regard, the numerical results have to be considered just as a sensitivity analysis focused on evaluating which formulation, needed to define the inflow conditions, makes the numerical model more reliable for urban flow simulation.

- Although the WT is one of the more reliable techniques used to validate CFD results, experimental uncertainties should always be critically assessed, such as those related to the flow angles. The range of the angular acquisition is $90^{\circ}$ and the uncertainty given by the supplier is $+/-0.5^{\circ}$. However, in regions where high flow gradients occur - for example near buildings walls - position inaccuracy may locally give rise to a significantly larger uncertainty which may affect the performance evaluation of both CFD cases.

In spite of these assumptions and limitations, the main outcome of this study was to show that the choice of the inflow conditions (mean velocity, turbulent kinetic energy and turbulence dissipation rate profiles) does not strongly affect the quality of the results in the urban canopy layer (UCL), as the two different conditions of Tominaga et al. (2008) and Richards and Hoxey (1993) present similar performances in terms of mean wind velocity (i.e. horizontal speed and direction analyzed in terms of yaw and pitch angles) and turbulent kinetic energy values. In particular:

- The mean wind speed contours showed small differences between the set 1 and set 2 cases for all wind directions considered, especially at lower heights, and the mean wind speed profiles fit properly the WT measurements.

- Small differences were found between both CFD cases and the WT case in terms of yaw angle, confirmed also by validation metrics $(R$ and FAC2.0).

- The turbulent kinetic energy profiles showed an unsatisfactory agreement between CFD and WT cases for all the analyzed wind directions in terms of absolute values, as they were systematically underpredicted. They were comparable in terms of shape, apart from the set 1 case for $\alpha=300^{\circ}$, which means that the urban texture of the numerical model forces the turbulence generation in the proper positions, while the turbulence model fails in predicting the correct amount of turbulence.

In general, the differences of $U$ and $k$ values between the set 1 and set 2 case are not significant as they are absolutely comparable. This result demonstrates primarily that the "large-scale forcing" imposed through the inflow conditions is not that relevant inside the UCL, so that it is probably useless to adopt more complex inflow conditions like the one suggested by Tominaga et al. (2008), at least in our case. However, it is worth noting that, while this is true for the turbulent kinetic energy $k(z)$ and turbulence dissipation rate $\varepsilon(z)$ profiles imposed at the inlet (very different in the Richards and Hoxey (1993) and Tominaga et al. (2008) formulations - see Figs. 5b,c and 6 b,c), it is not clear from the present analysis the role of the mean wind speed profiles since they are very similar in both cases (see Figs. 5a and 6 a). Also, it seems useless to consider the span-wise anisotropy of the flow in the WT, which is considered in the present study.

Moreover, it is well-known that the steady-state RANS approach has some difficulties in predicting mean and especially turbulent quantities in leeward zones, as behind buildings, at least for the commonly adopted turbulence models, as shown for instance in Yoshie et al. (2007). This is clearly demonstrated also in the present case by means of the statistical analysis reported in Section 5 , where all the analyzed quantities show better performances for $\alpha=240^{\circ}$ and $\alpha=270^{\circ}$, while the statistical indexes overall worsen for $\alpha=300^{\circ}$, for which the largest sheltering effects occur as "Canale Rosciano" becomes almost orthogonal with respect to the incoming wind direction.

It is generally accepted, indeed, that no RANS turbulence model is universally valid. In that regard, verification and validation studies are required to assess the performance of any given turbulence model for a specific problem (e.g. Ferziger, 1990, 1993; Ferziger \& Perić, 2002; Gosman, 1999; Shah \& Ferziger, 1997). This is true also for more complex models as eddy viscosity models (EVM, e.g. Launder, Reece, \& Rodi, 1975) or Reynolds stress models (RSM).However, no one of these two has shown a consistent superior performance with respect to the others for applications in building simulation (e.g. Ferziger, 1990; Murakami, 1997, 1998; Nielsen et al., 2007).

According to the main outcomes described above, the next steps of this systematic analysis about relevant parameters needed to optimize wind flow simulations in urban environment by the steady-RANS approach will focus on two different subjects. On the one hand, the role of the shape of the mean wind speed profile used as inflow condition has not been investigated here, since the two $U$ profiles adopted were very similar each other and superimposable to the WT measurements. Since it is not clear how this parameter can affect the CFD results, it would be worth to analyze this theme in the near future. On the other hand, the role of turbulence models on determining the characteristics of anisotropic flows (e.g. the ones occurring in the lee side of obstacles) is not dealt with in this paper, where conversely a modified $k-\varepsilon$ model (i.e. the realizable $k-\varepsilon$ ) has been adopted. In that regard, more sophisticated turbulence models could be tested systematically as a further development of this paper.

\section{Acknowledgements}

The authors gratefully acknowledge the Port Authority of Livorno 
for the use of data obtained by its anemometric monitoring network. All the monitoring devices and the HPC system at DICCA were funded by the European Cross-border Programme Italy/France "Maritime" 2007-2013 through the "Wind and Ports" (CUP: B87E09000000007) and "Wind, Ports, and Sea" (CUP: B82F13000100005) projects.

This research has been carried out in the framework of the Project "'Wind monitoring, simulation and forecasting for the smart management and safety of port, urban and territorial systems"', funded by Compagnia di San Paolo (grant number 2015.0333, ID ROL: 9820) in the period 2016-2018.

The authors acknowledge the TU1304 COST ACTION "WINERCOST".

The authors also thank the anonymous reviewers for their valuable comments on the manuscript.

\section{References}

An, K., Fung, J. C. H., \& Yim, S. H. L. (2013). Sensitivity of inflow boundary conditions on downstream wind and turbulence profiles through building obstacles using a CFD approach. Journal of Wind Engineering and Industrial Aerodynamics, 115, 137-149.

Armitt, J., \& Counihan, J. (1968). The simulation of the atmospheric boundary layer in a wind tunnel. Atmospheric Environment, 2, 49-71.

ASCE (2003). Minimum design loads for buildings and other structures. ASCE Standard (6th ed.). American Society of Civil Engineers.

Baker, C. J. (2007). Wind engineering-Past, present and future. Journal of Wind Engineering and Industrial Aerodynamics, 95(9-11), 843-870.

Balendra, T., Shah, D. A., Tey, K. L., \& Kong, S. K. (2002). Evaluation of flow characteristics in the NUS-HDB wind tunnel. Journal of Wind Engineering and Industrial Aerodynamics, 90, 675-688.

Barlow, J. F., et al. (2013). The wind that shakes the buildings: Wind engineering from a boundary layer meteorology perspective. In J. S. Owen (Ed.). Fifty years of wind engineering: Prestige lectures from the sixth European and African conference on wind engineering. University of Birmingham.

Barlow, T., Rae, W. H., Jr., \& Pope, A. (1999). Low-speed wind tunnel testing. John Wiley Sons, Inc.

Blocken, B. (2015). Computational fluid dynamics for urban physics: Importance, scales, possibilities, limitations and ten tips and tricks towards accurate and reliable simulations. Building and Environment, 91, 219-245.

Blocken, B. (2014). 50 years of computational wind engineering: Past, present and future. Journal of Wind Engineering and Industrial Aerodynamics, 129, 69-102.

Blocken, B. (2018). LES over RANS in building simulation for outdoor and indoor applications: A foregone conclusion? Building Simulation. https://doi.org/10.1007/ s12273-018-0459-3).

Blocken, B., Vervoort, R., \& van Hooff, T. (2016). Reduction of outdoor particulate matter concentrations by local removal in semi-enclosed parking garages: A preliminary case study for Eindhoven city center. Journal of Wind Engineering and Industrial Aerodynamics, 159, 80-98.

Blocken, B., Janssen, W. D., \& van Hooff, T. (2012). CFD simulation for pedestrian wind comfort and wind safety in urban areas: General decision framework and case study for the Eindhoven University campus. Environmental Modelling \& Software, 30, 15-34.

Blocken, B., Carmeliet, J., \& Stathopoulos, T. (2007). CFD evaluation of the wind speed conditions in passages between buildings-Effect of wall-function roughness modifications on the atmospheric boundary layer flow. Journal of Wind Engineering and Industrial Aerodynamics, 95, 941-962.

Blocken, B., Stathopoulos, T., \& Carmeliet, J. (2007). CFD simulation of the atmospheric boundary layer: Wall function problems. Atmospheric Environment, 41, 238-252.

Britter, R. E., \& Hanna, S. R. (2003). Flow and dispersion in urban areas. Annual Review of Fluid Mechanics, 35, 469-496.

Burlando, M., Tizzi, M., \& Solari, G. (2017). Characteristics of downslope winds in the Liguria Region. Wind and Structures, 24, 613-635.

Carpentieri, M., \& Robins, A. G. (2015). Influence of urban morphology on air flow over building arrays. Journal of Wind Engineering and Industrial Aerodynamics, 145, 61-74.

Cebeci, T., \& Bradshaw, P. (1977). Momentum transfer in boundary layers. New York: Hemisphere Publishing Corporation.

Cermak, J. E. (1972). Applications of fluid mechanics to wind engineering - a Freeman Scholar lecture. Transactions of the American Society of Mechanical Engineers. Journal of Fluids Engineering Series 1, 97, 9-38.

Chang, J. C., \& Hanna, S. R. (2004). Air quality model performance evaluation. Meteorology and Atmospheric Physics, 87, 167-196.

Cheng, W. C., \& Porté-Agel, F. (2015). Adjustment of turbulent boundary-layer flow to idealized urban surfaces: A large-eddy simulation study. Boundary—Layer Meteorology, 129, 1-23.

Coceal, O., \& Belcher, S. E. (2004). A canopy model of mean winds through urban areas. Quarterly Journal of the Royal Meteorological Society, 130, 1349-1372.

Counihan, J. (1969). An improved method of simulating an atmospheric boundary layer in a wind tunnel. Atmospheric Environment, 3, 197-214.

Counihan, J. (1970). Further measurements in a simulated atmospheric boundary layer. Atmospheric Environment, 4, 259-275.

Farell, C., \& Iyengar, A. K. S. (1999). Experiments on the wind tunnel simulation of atmospheric boundary layer. Journal of Wind Engineering and Industrial Aerodynamics,
$79,11-35$

Fernando, H. J. S. (2010). Fluid dynamics of urban atmospheres in complex terrain. Annual Review of Fluid Mechanics, 42, 365-389.

Fernando, H. J. S., Zajiic, D., Di Sabatino, S., Dimitrova, R., Hedquist, B., \& Dallman, A. (2010). Flow, turbulence and pollutant dispersion in urban atmospheres. Physics of Fluids, 22 051301-1-20.

Ferziger, J. H. (1990). Approaches to turbulent flow computation: Applications to flow over obstacles. Journal of Wind Engineering and Industrial Aerodynamics, 35, 1-19.

Ferziger, J. H. (1993). Simulation of complex turbulent flows: Recent advances and prospects in wind engineering. Journal of Wind Engineering and Industrial Aerodynamics, 46-47, 195-212.

Ferziger, J. H., \& Perić, M. (2002). Computational methods for fluid dynamics (third ed.). Springer-Verlag ISBN:3-540-42074-6.

Franke, J., Hellsten, A., Schlünzen, H., \& Carissimo, B. (2007). COST Action 732 quality assurance and improvement of microscale meteorological models.

García Sánchez, C., Philips, D. A., \& Gorlé, C. (2014). Quantifying inflow uncertainties for CFD simulations of the flow in downtown Oklahoma city. Building and Environment, 78, 118-129.

Gosman, A. D. (1999). Developments in CFD for industrial and environmental applications in wind engineering. Journal of Wind Engineering and Industrial Aerodynamics, 81, 21-39.

Gousseau, P., Blocken, B., \& van Heijst, G. J. F. (2013). Quality assessment of large-eddy simulations of wind flow around a high-rise building: Validation and solution verification. Computers \& Fluids, 79, 120-133.

Hanna, S. R., Brown, M. J., Camelli, F. E., Chan, S. T., Coirier, W. J., Hansen, O. R., et al. (2006). Detailed simulations of atmospheric flow and dispersion in downtown Manhattan. Bulletin of the American Meteorological Society, 87, 1713-1726.

Hertwig, D., Efthimiou, G. C., Bartzis, J. G., \& Leitl, B. (2012). CFD-RANS model validation of turbulent flow in a semi-idealized urban canopy. Journal of Wind Engineering and Industrial Aerodynamics, 111, 61-72.

Irwin, H. P. A. H. (1980). The design of spires for wind simulation. Journal of Wind Engineering and Industrial Aerodynamics, 7, 361-366.

Janssen, W. D., Blocken, B., \& van Hooff, T. (2013). Pedestrian wind comfort around buildings: Comparison of wind comfort criteria based on whole-flow field data for a complex case study. Building and Environment, 59, 547-562.

Kozmar, H. (2010). Scale effect in wind tunnel modeling of an urban atmospheric boundary layer. Theoretical and Applied Climatology, 100, 153-162.

Kozmar, H. (2011a). An alternative approach to experimental simulation of wind characteristics in urban environments. Procedia Environmental Sciences, 4, 43-50.

Kozmar, H. (2011b). Truncated vortex generators for part-depth wind-tunnel simulations of the atmospheric boundary layer flow. Journal of Wind Engineering and Industrial Aerodynamics, 99, 130-136.

Launder, B. E., \& Spalding, D. B. (1974). The numerical computation of turbulent flows. Computer Methods in Applied Mechanics and Engineering, 3, 269-289.

Launder, B. E., Reece, G. J., \& Rodi, W. (1975). Progress in the development of a Reynolds-stress turbulence closure. Journal of Fluid Mechanics, 68, 537-566.

Lloyd, A. (1967). The generation of shear flow in a wind tunnel. Quarterly Journal of the Royal Meteorological Society, 93, 79-96.

Meroney, R. N. (2016). Ten questions concerning hybrid computational/physical model simulation of wind flow in the built environment. Building and Environment, 96, $12-21$.

Moonen, P., Blocken, B., \& Roels, S. (2006). Numerical modelling of the flow conditions in a closed-circuit low-speed wind tunnel. Journal of Wind Engineering and Industrial Aerodynamics, 94, 699-723.

Murakami, S. (1990). Computational wind engineering. Journal of Wind Engineering and Industrial Aerodynamics, 36, 517-538.

Murakami, S. (1997). Current status and future trends in computational wind engineering. Journal of Wind Engineering and Industrial Aerodynamics, 67-68, 3-34.

Murakami, S. (1998). Overview of turbulence models applied in CWE-1997. Journal of Wind Engineering and Industrial Aerodynamics, 74-76, 1-24.

Computational fluid dynamics in ventilation design. In P. V. Nielsen, F. Allard, H. B. Awbi, L. Davidson, \& A. Schälin (Eds.). REHVA guidebook no. 10 (pp. 103).

Patankar, S. V. (1980). Numerical heat transfer and fluid flow. McGraw-Hill Book Company ISBN: 0-07-048740-5.

Wind tunnel modelling of wind effects in engineering. In E. J. Plate (Ed.). Engineering meteorology (pp. 573-639). Amsterdam: Elsevier Chapter 13).

Plate, E. J. (1999). Methods of investigating urban wind fields - physical models. Atmospheric Environment, 33, 3981-3989.

Razak, A. A., Hagishima, A., Ikegaya, N., \& Tanimoto, J. (2013). Analysis of airflow over building arrays for assessment of urban wind environment. Building and Environment, 59, 56-65.

Repetto, M. P., Burlando, M., Solari, G., De Gaetano, P., \& Pizzo, M. (2017). Integrated tools for improving the resilience of seaports under extreme wind events. Sustainable Cities and Society, 32, 277-294.

Repetto, M. P., Burlando, M., Solari, G., De Gaetano, P., Pizzo, M., \& Tizzi, M. (2017). A web-based GIS platform for the safe management and risk assessment of complex structural and infrastructural systems exposed to wind. Advances in Engineering Software, 117, 29-45.

Ricci, A., Burlando, M., Freda, A., \& Repetto, M. P. (2017). Wind tunnel measurements of the urban boundary layer development over a historical district in Italy. Building and Environment, 111, 192-206.

Ricci, A., Kalkman, I., Blocken, B., Burlando, M., Freda, A., \& Repetto, M. P. (2017). Localscale forcing effects on wind flows in an urban environment: Impact of geometrical simplifications. Journal of Wind Engineering and Industrial Aerodynamics, 170, 238-255.

Richards, P. J., \& Hoxey, R. P. (1993). Appropriate boundary conditions for 
computational wind engineering models using the k- $\varepsilon$ turbulence model. Journal of Wind Engineering and Industrial Aerodynamics, 46-47, 145-153.

Schatzmann, M., Olesen, H., \& Franke, J. (2010). COST 732 model evaluation case studies: Approach and results. COST Action 732.

Shah, K. B., \& Ferziger, J. H. (1997). A fluid mechanicians view of wind engineering: Large eddy simulation of flow past a cubic obstacle. Journal of Wind Engineering and Industrial Aerodynamics, 67-68, 211-224.

Shih, T. H., Liou, W. W., Shabbir, A., \& Zhu, J. (1995). A new k- $\varepsilon$ eddy-viscosity model for high reynolds number turbulent flows. Computers \& Fluids, 24, 227-238.

Solari, G., Repetto, M. P., Burlando, M., De Gaetano, P., Parodi, M., Pizzo, M., et al. (2012). The wind forecast for safety management of port areas. Journal of Wind Engineering and Industrial Aerodynamics, 104-106, 266-277.

Stathopoulos, T. (1997). Computational wind engineering: Past achievements and future challenges. Journal of Wind Engineering and Industrial Aerodynamics, 67-68, 509-532.

Tominaga, Y., \& Stathopoulos, T. (2013). CFD simulation of near-field pollutant dispersion in the urban environment: A review of current modelling techniques. Atmospheric Environment, 79, 716-730.

Tominaga, Y., Mochida, A., Yoshie, R., Kataoka, H., Nozu, T., Yoshikawa, M., et al. (2008). AIJ guidelines for practical applications of CFD to pedestrian wind environment around buildings. Journal of Wind Engineering and Industrial Aerodynamics, 96, 1749-1761.
Tse, K., Weerasuriya, A., Zhang, X., Li, S., \& Kwok, K. (2017). Pedestrian-level wind environment around isolated buildings under the influence of twisted wind flows. Journal of Wind Engineering and Industrial Aerodynamics, 162, 12-23.

van Hooff, T., \& Blocken, B. (2010). Coupled urban wind flow and indoor natural ventilation modelling on a high-resolution grid: A case study for the Amsterdam ArenA stadium. Environmental Modelling \& Software, 25, 51-65.

Versteeg, H. K., \& Malalasekera, W. (2007). An introduction to computational fluid dynamics: The finite volume method. London: Harlow-Longman Scientific \& Technical.

Weerasuriya, A. U., Hu, Z. Z., Zhang, X. L., Tse, K. T., Li, S., \& Chan, P. W. (2018). New inflow boundary conditions for modeling twisted wind profiles in CFD simulation for evaluating the pedestrian-level wind field near an isolated building. Building and Environment, 132, 303-318.

Xie, Z., \& Castro, I. P. (2006). LES and RANS for turbulent flow over arrays of wallmounted obstacles. Flow Turbulence Combustion, 76, 291-312.

Xie, Z., Coceal, O., \& Castro, I. P. (2008). Large-eddy simulation of flows over random urban like obstacles. Boundary-Layer Meteorology, 129, 1-23.

Yoshie, R., Mochida, A., Tominaga, Y., Kataoka, H., Harimoto, K., Nozu, T., et al. (2007) Cooperative project for CFD prediction of pedestrian wind environment in the Architectural Institute of Japan. Journal of Wind Engineering and Industrial Aerodynamics, 95, 1551-1578. 